2019-04

Foundations of offshore wind turbines: $A$ review

$\mathrm{Wu}, \mathrm{X}$

http://hdl.handle.net/10026.1/17685

10.1016/j.rser.2019.01.012

Renewable and Sustainable Energy Reviews

Elsevier BV

All content in PEARL is protected by copyright law. Author manuscripts are made available in accordance with publisher policies. Please cite only the published version using the details provided on the item record or document. In the absence of an open licence (e.g. Creative Commons), permissions for further reuse of content should be sought from the publisher or author. 


\title{
Foundations of offshore wind turbines: a review
}

\author{
Xiaoni $\mathrm{Wu}^{\mathrm{a}, \mathrm{b}, \mathrm{e}}, \mathrm{Yu} \mathrm{Hu}$, , Ye Li*a,b,c,de ${ }^{\text {, Jian Yang }}{ }^{\mathrm{b}}$, Lei Duan ${ }^{\mathrm{a}, \mathrm{b}, \mathrm{e}}$, Tongguang Wang ${ }^{\mathrm{f}}$, Thomas Adcock ${ }^{\mathrm{g}}$, \\ Zhiyu Jiang ${ }^{\mathrm{h}}$, Zhen Gao ${ }^{\mathrm{i}}$, Zhiliang Lin ${ }^{\mathrm{a}, \mathrm{b}, \mathrm{c}}$, Alistair Borthwick', Shijun Liao ${ }^{\mathrm{a}, \mathrm{b}, \mathrm{c}}$ \\ ${ }^{a}$ State Key Laboratory of Ocean Engineering, School of Naval Architecture, Ocean and Civil Engineering, Shanghai Jiao Tong University, Shanghai 200240, China \\ ${ }^{b}$ School of Naval Architecture, Ocean \& Civil Engineering, Shanghai Jiao Tong University, Shanghai 200240, China \\ ${ }^{c}$ Collaborative Innovation Center for Advanced Ship and Deep-Sea Exploration, Shanghai Jiao Tong University, Shanghai 200240, China \\ ${ }^{d}$ Key Laboratory of Hydrodynamics (Ministry of Education), Shanghai Jiao Tong University, Shanghai 200240, China \\ ${ }^{e}$ Muti-function Towing Tank, Shanghai Jiao Tong University, Shanghai 200240, China \\ ${ }^{f}$ College of Aerospace Engineering, Nanjing University of Aeronautics and Astronautics, Nanjing 210016, China \\ ${ }^{g}$ Department of Engineering Science, University of Oxford, Oxfordshire, United Kingdom \\ ${ }^{h}$ Department of Engineering Sciences, University of Agder, $N-4879$ Grimstad, Norway. \\ ${ }^{i}$ Department of Marine Technology, Norwegian University of Science and Technology, NO-7491 Trondheim, Norway \\ ${ }^{j}$ School of Engineering, The University of Edinburgh, Edinburgh EH9 3JL, United Kingdom
}

\begin{abstract}
Offshore wind is a source of clean, renewable energy of great potential value to the power industry in the context of a low carbon society. Rapid development of offshore wind energy depends on a good understanding of technical issues related to offshore wind turbines, which is spurring ongoing research and development programmes. Foundations of offshore wind turbines present one of the main challenges in offshore wind turbine design. This paper reviews the present state of knowledge concerning geotechnical and structural issues affecting foundation types under consideration for the support structures of offshore wind turbines, and provides recommendations for future research and development.
\end{abstract}

Keywords: Offshore wind turbine, offshore foundations, monopile, bucket foundation, anchors

\section{$1 \quad$ Introduction}

\subsection{Development of offshore wind energy}

Renewable energy has become increasingly important over recent decades as a means of achieving international targets for reduced greenhouse gas emissions while ensuring energy security. Of the various sources of clean and renewable energy, wind energy has proved particularly attractive. At the end of 2012, developed countries, China, and India generated over $95 \%$ of the global installed capacity, and more than 
$60 \%$ of the global wind power capacity located in Europe and North America [1]. It is estimated that over $20 \%$ of the world's electricity demands will be met by wind energy by 2050 [2].

Onshore and offshore production present two different alternatives for wind energy. Onshore wind energy has been utilised for over 2000 years and has undergone an extremely successful technological revolution in recent years. The bar chart in Fig.1 illustrates the ongoing and forecast status of onshore and offshore wind energy installations throughout the world during the present decade from 2011 to 2020 [3]. Although some way behind onshore wind, it can be seen that offshore wind energy production has started to accelerate. Offshore wind farms are gradually beginning to flourish as offshore wind energy technology matures.

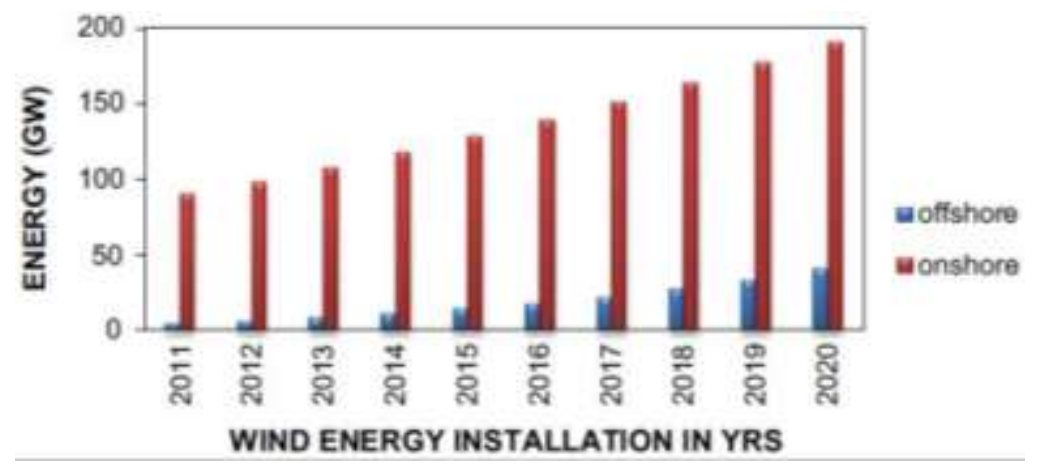

Fig.1. Offshore and onshore wind energy installations: 2011-2020 [3]

By 2030, the EU will invest almost 20 billion Euros in the wind power market, of which $60 \%$ is aimed at the offshore wind market [4]. Meanwhile, the offshore wind industry in Asia-Pacific area is also booming. Unlike Europe, offshore wind farms in China are being located close to densely populated areas whereas onshore wind farms are located far from the main cities. The offshore wind power resource of China is estimated to be about $200 \mathrm{GW}$, almost 10 times present onshore installed capacity, and has huge potential [5]. The first offshore wind farm in Asia-Pacific area is located near Shanghai, and has an installed generation capacity of 102 MW. A further large-scale wind farm of about $1 \mathrm{GW}$ installed capacity is planned for Shanghai by 2020 [6].

From the point of view of investment per megawatt (MW), offshore wind is still some $50 \%$ more expensive than onshore wind. Typically, offshore wind turbines are $20 \%$ more expensive, and towers and foundations $350 \%$ more costly than similar onshore counterparts [7]. Based on NREL's statistical data for 2015 offshore wind projects, capital expenditure for offshore wind in 2015 was mainly on wind turbines, assembly and installation, and substructure and foundations. For bottom-fixed offshore wind platforms, the turbine is the 
most expensive item, contributing about $31.8 \%$ to the overall cost, while the second and third most expensive parts are assembly and installation (19.3\%), followed by substructure and foundations (14.7\%) [8]. For floating offshore wind platforms, the substructure and foundations are the most expensive components (36.2\%). Turbines, and their assembly and installation take up about $22.1 \%$ and $11.1 \%$ of the total cost [8]. Due to the high cost of the substructure and foundations of floating platforms, there is a large overall cost differential between fixed-bottom and floating offshore wind projects.

\subsection{Rationale}

As offshore wind energy exploration has gathered pace in waters and, more recently, deeper waters, foundations supporting both fixed and floating offshore wind turbine structures have become a focus of interest to the offshore wind industry, owing to their importance regarding stability of the offshore wind turbine structures. The foundations of offshore wind farms are subject to a complex combination of loadings, including the axial force from the turbine support structure and cyclic loads from extreme sea states. Such foundations must be designed to resist very large numbers of wind and hydrodynamic load cycles of varying direction, amplitude, and frequency that occur over a project's typical design life of 25 years or so [9]. Design and installation of foundations present engineers with challenging problems, whose solution is critically important for development of the offshore wind industry.

In view of the ongoing growth of the offshore wind industry and the relatively limited development of foundation technology for offshore wind turbines, this paper reviews current progress towards accurate analysis and design of offshore wind turbine foundations. We examine existing research on geotechnical and structural issues, paying particular attention to common monopile foundations for fixed offshore wind turbine structures, and bucket foundations and offshore anchors for floating offshore wind turbine structures. The resulting recommendations for future research and development of offshore wind turbine foundations should be useful to the offshore wind industry.

\section{Offshore wind foundations}

\subsection{Offshore wind turbine structures}

The majority of offshore wind farms are located on the continental shelf, about $10 \mathrm{~km}$ off the coast in water depths of about $10 \mathrm{~m}$. Offshore wind production is much more complicated than onshore in terms of design of the wind turbine system and construction of the wind farm [10]. Offshore wind turbines must be located above the crest level of the highest waves, and have strong support structures connected to the seabed by foundations. Submarine cable and other electricity transmission systems are required for erection and 
maintenance work, which may result in much higher costs of offshore wind installations than onshore towers [11]. It has been estimated that the cost of a typical offshore wind unit is double or triple that of an onshore wind unit $[10,12]$ depending on location. Site selection for offshore wind farms is more flexible in terms of space constraints than for onshore wind farms. Moreover, offshore wind installations are usually located far from densely populated areas, with reduced noise and visual impacts on communities.

Existing installed offshore wind turbines mostly comprise wind turbines with fixed foundations, such as gravity base, monopile, tripod and jacket foundations, installed in water depths of less than $50 \mathrm{~m}$. For water depths greater than $50 \mathrm{~m}$, the wind resource is substantial but bottom-fixed offshore wind turbines are no longer an economic proposition for resource exploitation. Many coastal countries such as Japan, the United States and west European countries with an Atlantic seaboard have limited coastal territorial waters of water depth below $50 \mathrm{~m}$ [13]. Consequently, floating offshore wind turbines have attracted much interest in the past 10 years. Fig. 2 depicts examples of typical support structures for offshore wind turbines used in different water depths. Industrially-funded research on floating wind turbines started in the mid-1990s, following an initial concept proposed by William E Heronemus at the University of Massachusetts Amherst in the early 1970s [14]. Floating offshore wind turbines with mooring systems and anchor foundations have been proposed and tested, benefiting from advances in the floating oil and gas platforms such as tension leg platforms (TLPs), semi-submersibles, and spars, as shown in Fig. 3. These three types of floating structures have all seen application to floating wind turbines. The first test floating wind turbine (TLP platform type) was installed by Blue H Technologies off the Italian coast with a rated capacity of $80 \mathrm{~kW}$ in 2008 [14]. In 2009, the world's first MW-scale floating wind turbine, Hywind with a capacity of 2.3MW and a spar foundation, was installed by Statoil in the North Sea near Norway [14]. In 2011, WindFloat was developed by Principle Power Inc. with a 2 MW Vestas turbine, and installed 4 km offshore of Aguçadoura, Portugal in approximately $45 \mathrm{~m}$ water depth [14]. WindFloat has a semisubmersible foundation and is the second MW-scale floating wind turbine. In an overview of floating wind turbine concepts, Castro-Santos and DiazCasas [14] note that there is no consensus as to which type of floating wind concept should be deployed at large scale in the future. The development of floating wind turbine technology evidently requires more research before widespread application. 


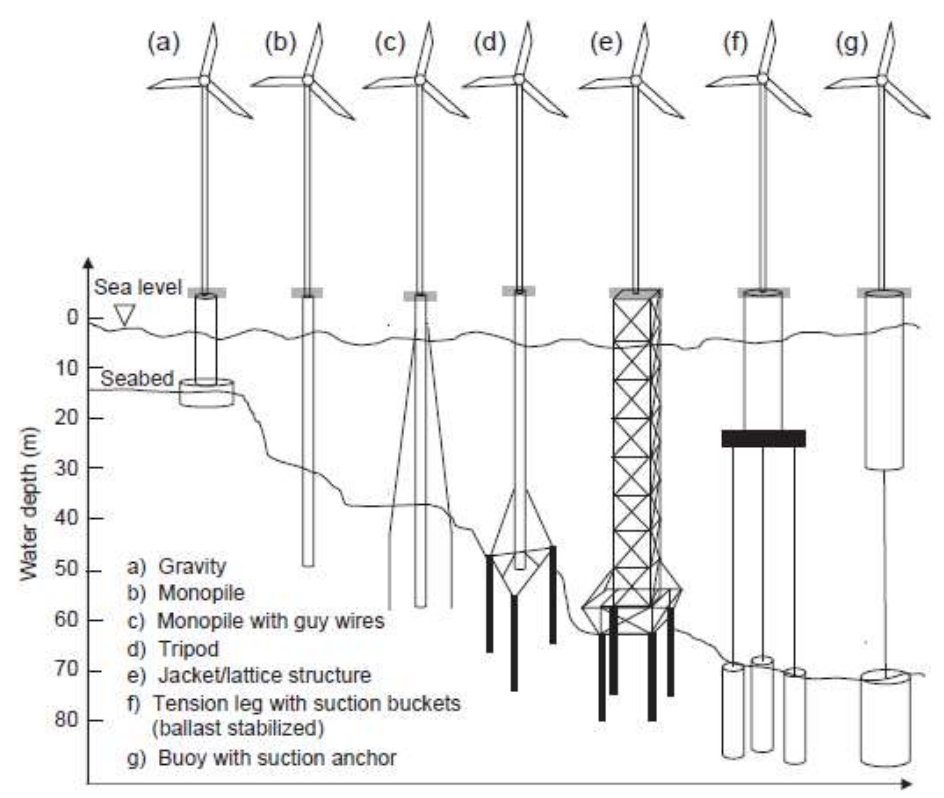

Fig.2. Typical support structure options applicable at different water depths [13]

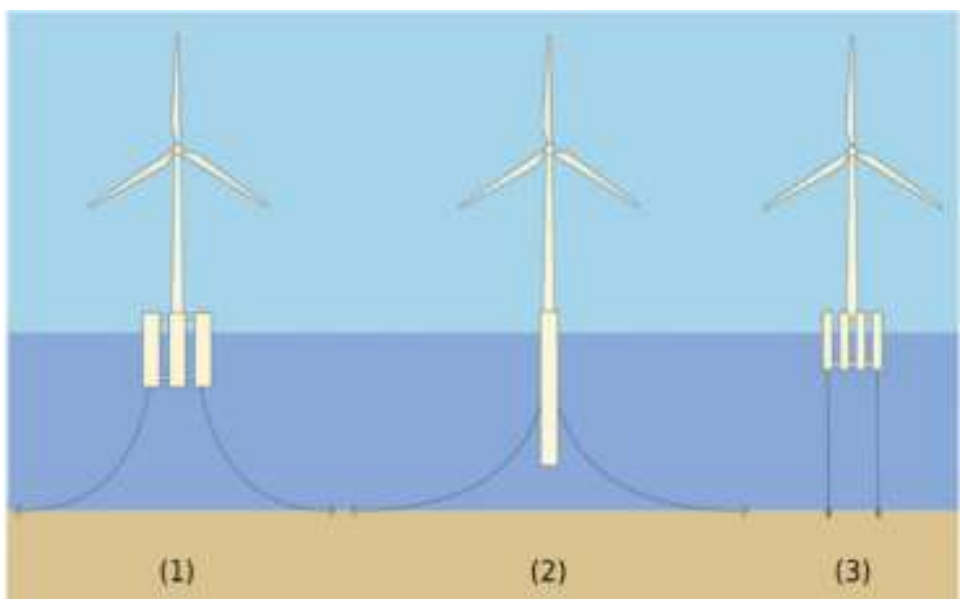

Fig.3. Floating wind turbine concepts: (1) semi-submersible platform; (2) spar; and (3) tension leg platform (TLP) [14]

\subsection{Types of offshore wind turbine foundation}

According to inventory data [15], the investment in foundations accounts for $20 \%$ to $30 \%$ of the cost of a typical offshore wind farm. This contributes to the higher cost of offshore wind turbines than of onshore ones. Therefore, selection of a suitable foundation type for offshore wind turbines is key to exploitation of offshore wind energy. Fig.4 presents a schematic diagram of four typical support structures used for fixed offshore wind turbines. We now review in turn commonly applied types of offshore wind turbine foundations and anchorages of mooring systems for prospective deep-water floating wind farms. 


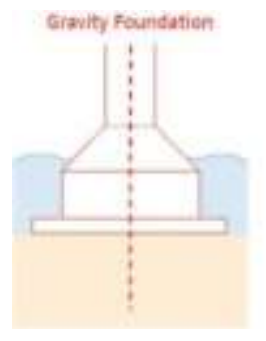

a. Gravity

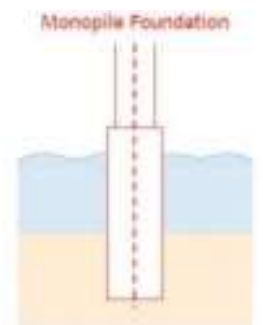

b. Monopile

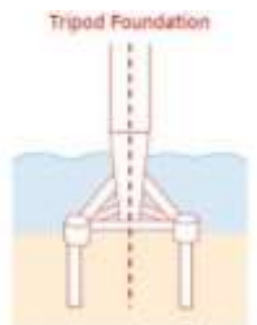

c. Tripod

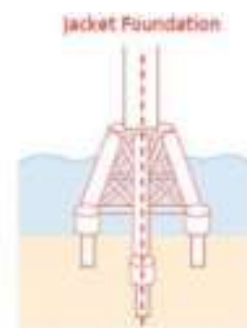

d. Jacket

Fig.4. Schematic diagram illustrating bottom-fixed offshore wind turbine foundations [16]

\subsubsection{Gravity base foundations}

Design of gravity base foundations of offshore wind turbines is primarily according to their self-weight, which must be sufficient to resist extreme overturning moments, leaving support structures standing upright on the seabed. Fig.4a provides a schematic illustration of a gravity base. As a type of reinforced concrete caisson structure, the gravity base is simple to construct and has a relatively low load bearing capacity. Given that the gravity base requires sufficient load bearing capacity to support the self-weight, service loads, and environmental loads acting on the foundation structures, gravity base foundations are more appropriate for seabeds composed of compacted clay, sandy soil, and rock. Gravity base foundations are usually situated in water depths less than $10 \mathrm{~m}$. During the early stages of offshore wind development, the majority of offshore wind turbines adopted gravity base foundations, such as Vindeby (1991), Tunø Knob (1995), Middelgrunden (2001), Nysted (2004) and Sprogø (2009) in Denmark [17], Lillgrund (2008) in Sweden, and Thorntonbank (2009) and Belwind (2011) in Belgium.

\subsubsection{Monopile foundations}

A typical monopile foundation is composed of a single steel tube pile of diameter of 3 to $8 \mathrm{~m}$ (Fig.4b). Monopiles are usually located in water of relatively shallow water depth, ranging between 20 to $40 \mathrm{~m}$. It is unclear as to what is the water depth at which monopile foundations become uneconomic. Monitoring of installed structures indicates that actual foundations offer greater stiffness than predicted by existing design methods [18]; more accurate design methods are needed to reduce the weight and required embedment of monopile foundations [19]. For seabed with clay, sand, or chalk stratigraphy, monopiles can be installed using impact hammers or vibratory driving. For a rocky seabed, drilling and bored pile methods are commonly adopted. Due to its ease of manufacture, low cost, and manageable construction, the monopile has been utilised worldwide for offshore wind turbine foundations. Examples include wind farms at Blyth, UK (2000) [20], North Hoyle, UK (2003) [21], Scroby Sands, UK (2004) [22], Kentish Flats, UK (2005) [23], Bockstigen, Sweden (1997) [24,25], Yttre Stengrund, Sweden (2001) [25], Utgrunden, Sweden (2002) 
[26], Arklow Bank, Ireland (2003) [27], Lely, The Netherlands (1994) and Egmond aan Zee, The Netherlands (2007) [28].

\subsubsection{Tripod foundations}

Tripod foundations (Fig.4c) comprise three medium diameter steel pipe piles arranged in an equilateral triangle, the apex of which supports the upper tripod truss structure. As a precast unit, a tripod truss can bear upper loads applied to tower and deliver stresses and moments to the three steel piles. The tripod foundation is stable, lightweight, and suitable for application in water depths of 10 to $35 \mathrm{~m}$. Examples include Alpha Ventus, Germany (2010) [29] and Nogersund, Sweden (1990) [30].

\subsubsection{Jacket (lattice structure) foundations}

The jacket foundation (Fig.4d) comprises a space frame structure assembled from steel tubular members, which is usually fabricated in advance by welding on land. The jacket is then transported to site, and piled into the seabed. Jacket foundations are relatively economical in terms of steel consumption, but storage, logistics, and installation can be expensive, substantially raising the overall cost [31]. To date, jacket foundations have been widely used in intermediate water depths ranging from 5 to $50 \mathrm{~m}$. Examples include Alpha Ventus, Germany (2010) [29], Beatrice, UK (2006) [32], and Ormonde, UK (2012). The first Chinese offshore wind turbine demonstration project in Bohai Sea also adopted jacket foundations.

\subsubsection{Tension leg with suction buckets}

Suction bucket foundations, otherwise known as suction caisson or suction pile foundations (Fig.2 f \&g), can be divided into single-bucket and multi-bucket caisson foundations. Bucket foundations are most suitable for seabed composed of soft clay and for wind turbines in water of varying depth. Owing to the special installation method used, the installation cost of a suction bucket foundation is lower than that of an equivalent offshore pile foundation. It is also more convenient to transport suction bucket foundations at sea. Suction bucket foundations are gradually becoming popular in the offshore wind turbine industry, an example being at Frederikshavn, Denmark (2003) [33]. Although the suction bucket foundation appears a promising solution, its reliability requires further verification.

\subsubsection{Anchors for floating offshore wind turbine}

A floating structure with a mooring system mounted by anchors at the seabed is perhaps the best option for

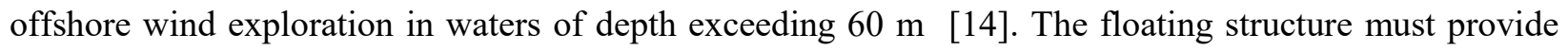
sufficient buoyancy to support the weight of the turbine and to restrain pitch, roll, and heave motions within acceptable limits [14]. As the focus increases on wind energy exploitation in deep water, new concepts for floating offshore wind turbines are likely to be proposed. In the not too distant future, offshore wind turbines 
will be installed on floating platforms presently used by the offshore oil and gas industry [34], including semi-submersible platforms, spars, and TLPs (Fig.3). In late 2007, Blue H Technologies of The Netherlands installed the first floating offshore wind turbines in the Mediterranean Sea off the coast of Italy [35]. This was followed by a second installation, Hywind [35], constructed by Siemens Wind Power in the North Sea in 2009. Floating wind turbines with mooring systems have to meet twin requirements of performance stability and cost saving. For such offshore wind turbines, the floating structure is tethered through mooring systems to the seabed by anchors. Typical anchorage types include gravity anchors (deadweight anchors), anchor piles, drag embedment anchors (DEAs), vertical loaded anchors (VLAs), suction caissons, suction embedded plate anchors (SEPLAs), torpedo anchors, and deep penetrating anchors (DPAs) (or dynamically embedded anchors), as shown in Fig.5 [36].

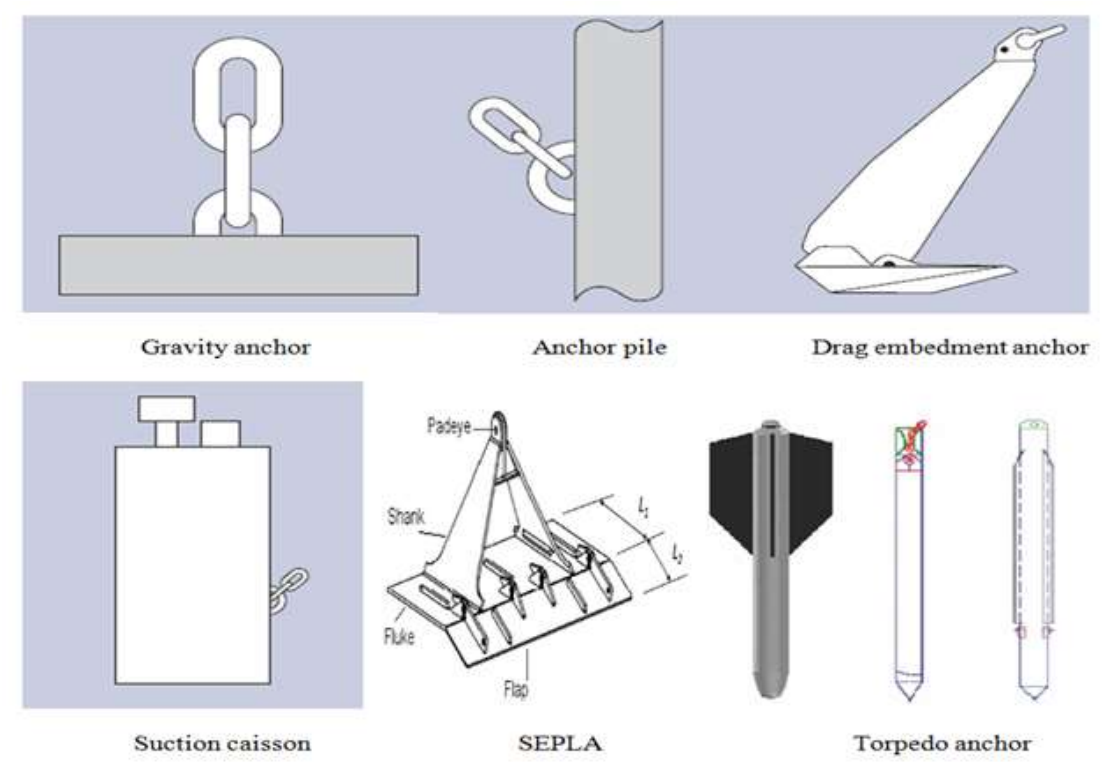

Fig.5. Geometry of different anchor types (Reproduced from Wu (2017)) [36]: gravity anchor [37], anchor pile [37], drag embedment anchor (DEA) [37], suction caisson [37], suction embedded plate anchor (SEPLA) [38], and torpedo anchor [39]

Gravity anchors are hollow boxes filled with high-density material. Their load capacity derives from deadweight and friction at the seabed. Anchor piles are normally composed of hollow steel pipes driven into the seabed by piling hammers. The holding capacity arises mainly from friction along the pile-soil interface. A drag anchor is composed of a fluke and a shank, which are dragged into the seabed. Anchor capacity depends on the soil properties at the final position and the fluke area. Conventional drag anchors are drag embedment anchors (DEAs). Drag anchors that can bear vertical loads are called vertically loaded anchors (VLAs). The suction caisson is a hollow cylinder with a cap, which is installed by the pressure 
difference created by pumping water from the caisson. Friction and end bearing provide the holding capacity. A suction embedded plate anchor (SEPLA) is a kind of follower embedded anchor. SEPLA is composed of a rectangular flat fluke anchor with a keying flap. The suction caisson is used to install the fluke plate as a follower. The concepts of torpedo anchor (patented by Petrobras in 1996) and deep penetrating anchor (DPA) are similar [39] in that both comprise large arrow-shaped anchors installed by dropping them from a determined height above the seabed and embedment achieved through kinetic energy [36].

Exploitation of wind energy at water depths over $60 \mathrm{~m}$ is possible in the future using floating wind turbines with mooring systems in offshore farms. Floating offshore wind turbines with mooring systems based on different anchorage types are prospective future alternatives for harvesting offshore wind energy. However, this perspective relies on a mature technology developing for combining floating structures with offshore wind turbine structures. As floating wind turbine technology is still nascent, the application of large offshore platforms to host wind turbines is presently limited.

\section{Studies on offshore wind turbine foundations}

To promote technology development, research studies on foundations of offshore wind turbine have investigated geotechnical issues, including foundation capacity, installation and foundation/soil interface modelling, and structural issues such as structural response and fatigue analysis. We discuss this further, below.

\subsection{Geotechnical issues concerning monopiles}

The monopile foundation of an offshore wind turbine typically has a slenderness ratio (embedment depth over diameter) less than 10 [13]. Both the outer diameter and penetration depth of a monopile driven into the soil of the seabed depend on the power generation capacity of the wind turbine supported by the monopile. Installed monopile foundations commonly have outer diameters of 4 to $12 \mathrm{~m}$, and penetration depths of between 20 and $40 \mathrm{~m}$. The typical slenderness ratio has fallen from a value of approximately 5 for the early installations, to 3 or less for the most recent designs as the adopted design methods have become progressively less conservative. In practice, the embedded portion may be assumed to behave as a rigid structure. The monopile should be designed to satisfy ultimate, serviceability, and long-term fatigue load conditions [13]. Due to the geometry of offshore wind turbine structures, the horizontal loading from wind and waves produces large bending moments, which dictate foundation design. Existing investigations into geotechnical issues related to monopile foundations have focused mainly on the bearing capacity of monopiles under different loadings, the load-deflection response of monopiles, the modelling of pile-soil interaction in structural response studies, and scour around monopiles. 


\subsubsection{Capacity and behaviour of a monopile under different loading conditions}

Offshore wind turbine monopile foundations must be designed to have sufficient embedment depth and diameter to ensure lateral stability. In practice, stability analyses of a monopile are usually performed for separate axial and lateral load cases. Due to the rather limited information available on the interaction effect of monopile behaviour under combined axial and lateral loading, a systematic, sophisticated analysis is required. Here, we review monopile stability studies according to: (1) axial loading capacity and settlement response; (2) lateral loading capacity and flexural behaviour; and (3) monopile behaviour under combined axial and lateral loading.

\section{Axial stability}

According to O'Kelly and Arshad [13], an equation for predicting the axial load-carrying capacity of pile under static loading given by API [40] has been widely employed by the research community (see e.g. Igoe et al. [41], Haiderali et al. [42], and Bisoi and Haldar [43]) for monopile axial capacity analysis. In this case, the ultimate axial load-carrying capacity $\left(Q_{\mathrm{d}}\right)$ of a monopile is determined from:

$$
Q_{\mathrm{d}}=Q_{\mathrm{f}}+Q_{\mathrm{p}}=\mathrm{f} A_{\mathrm{s}}+q A_{\mathrm{p}}
$$

where $Q_{\mathrm{f}}$ is skin friction resistance $(\mathrm{kN}), Q_{\mathrm{p}}$ is total end bearing $(\mathrm{kN}), \mathrm{f}$ is unit skin friction capacity,

$(\mathrm{kPa}), A_{\mathrm{s}}$ is side surface area of pile $\left(\mathrm{m}^{2}\right), q$ is unit end bearing capacity $(\mathrm{kPa})$, and $A_{\mathrm{p}}$ is gross end area of pile $\left(\mathrm{m}^{2}\right)$. Haiderali et al. [42] investigated the axial response of monopiles installed in undrained clays of varying shear strength and stiffness using three-dimensional finite element analysis. The axial capacities obtained from the finite element analysis were found to be in satisfactory agreement with results calculated using equation (1). For different soil conditions, API [40] recommend values for the calculation parameters related to the shaft friction and end bearing. Given that pile axial deflections should be within acceptable serviceability limits and deflections should be compatible with structural forces and displacements, API [40] also provide an equation for estimating the static load deflection behaviour and cyclic response of a pile under cyclic loading, which was developed under environmental conditions for the performance of an axial pile. Studies by Gavin and O'Kelly [44] and Igoe et al. [45] show that that degradation of shaft friction capacity due to cyclic axial loading can lead to the accumulation of displacements which may ultimately cause severe reduction in axial load-carrying capacity [13].

\section{Lateral stability}


Most designs of monopiles under lateral loading carried out in industry are based on practical guidelines provided by API [40] and DNVGL [46]. The traditional $p-y$ curve method (where $p$ is the lateral soil resistance and $y$ is the lateral deflection) treats the foundation as a beam supported by uncoupled lateral springs to represent soil reactions, depending on soil type and loading conditions. Cyclic lateral loads govern the design, whilst the axial loading case checks that serviceability is satisfied. To design a monopile under lateral loading, it is still necessary to check values of lateral deflection (occurring at seabed level) and rotation of the monopile. Fig. 6 shows the lateral deformation and rotation of monopile under static lateral loading. The lateral loads lead to the pile displacement (the lateral deformation at seabed $y_{s}$ ) and rotation (angle $\phi$ at seabed) [47].

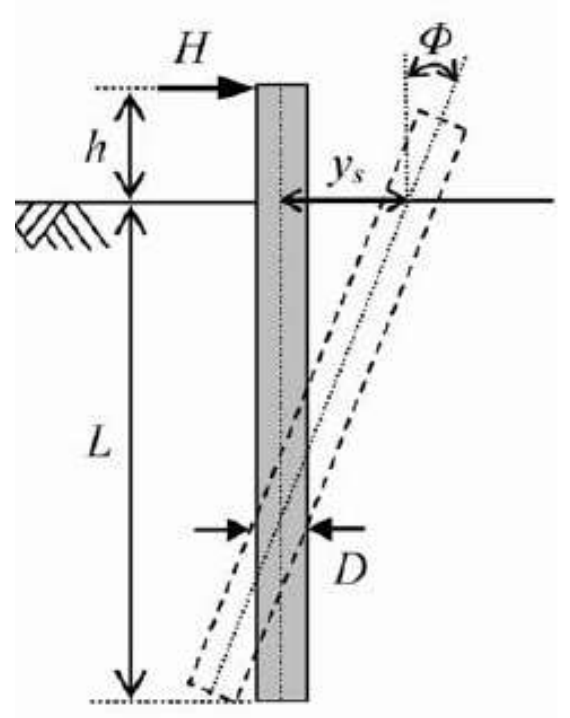

Fig.6. Lateral deformation and rotation of monopile under static lateral loading[47] (monopile diameter $\mathrm{D}$, embedment depth L, distance of pile head above the soil surface $\mathrm{h}$, lateral load $\mathrm{H}$ )

Early calculation methods for deflection proposed by Randolph [48], Broms [49], and Matlock and Reese [50] relate to monotonic loading conditions and do not consider the number of lateral load cycles [13]. Although API [40] and DNVGL [46] codes are widely used, the calculation methods given in these codes and the traditional $p-y$ curve method are based on data from small diameter piles and long flexible piles. These methods are not strictly suitable for the design of a monopile under lateral loading. Haiderali et al. [51] indicated that the deformation mechanism is fundamentally different from that of a small diameter laterally loaded pile; the monopile is stiff and deforms primarily through rigid body rotation about a pivot point whereas the latter is flexible and deforms in bending. Studies of the lateral behaviour of a monopile based on numerical analysis have been undertaken in developing numerical techniques and constitutive 
models. Ahmed et al. [52] conducted three-dimensional (3D) finite element (FE) analyses to evaluate the lateral capacity of large diameter monopiles in dense sand using the Arbitrary Lagrangian-Eulerian (ALE) approach in Abaqus/Explicit FE software. Sand behaviour was modelled using Mohr-Coulomb (MC) and modified Mohr-Coulomb (MMC) models which considered pre-peak hardening, post-peak softening, and the effects of mean effective stress and relative density on stress-strain behaviour of dense sand. It was found that the MMC model provided better simulations of the load-displacement response than the MC model when comparing the numerical predictions with physical model test data. The PISA project [19] has presented a new framework for predicting the monotonic lateral behaviour of a monopile foundation, by using the state-of-the-art 3D FE modelling, validated through a medium scale field testing campaign, to calibrate the soil reactions for a simplified and quick to run 1D FE model. Fig.7 shows the framework for the proposed 1D finite model for a monopile. The proposed model extended the traditional $p-y$ method by incorporating additional soil reaction terms (the corresponding relationship curves) to represent the largediameter effect of a monopile [53]. $\mathrm{H}$ is the lateral load at the head of monopile, the relationship between distributed load $p$ and lateral pile displacement $v$ is defined by the distributed load curve; the distributed moment curve defines the relationship between the distributed moment $m$ and the cross-section rotation $\theta$; the base shear curve defines the relationship between the base shear force $S$ and the lateral displacement of pile toe $v$; the base moment curve is used to define the relationship between the base moment $M$ and the rotation of the monopile toe $\theta[53]$.

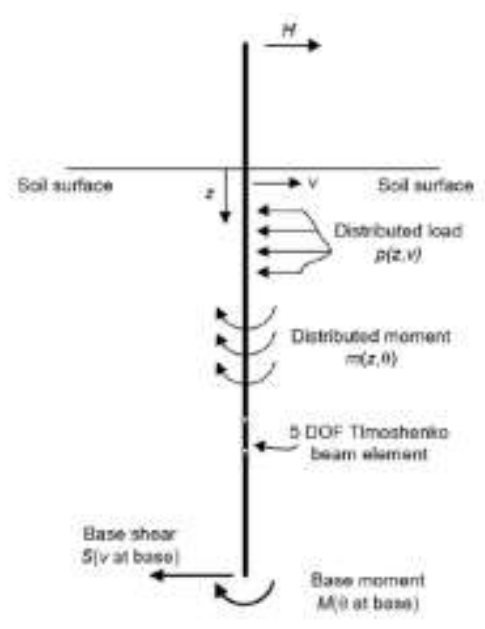

Fig.7. Framework for the proposed 1D finite model for monopile foundations(Reproduced from Byrne et al.(2015) )[53]

Having gained an understanding of the importance of cyclic loading on the monopile lateral capacity and deflection, researchers investigated the effects of short-term and long-term cyclic lateral loadings. Carswell 
et al. [54] indicated that for a monopile in clay, the undrained clay behaviour under short-term cyclic soilpile loading (e.g. extreme storm conditions) typically includes plastic soil deformation resulting from reductions in soil modulus and undrained shear strength which occur as a function of pore pressure buildup. Carswell et al. [54] conducted analyses using novel combinations of existing $p$ - $y$ curve design methods to study the impact of short-term cyclic loading on a monopile in soft, medium, and stiff clay. It was found that short-term cyclic loading from extreme storm conditions is unlikely to affect significantly the natural frequency and permanent accumulated rotation of OWT monopiles in stiff clays, whereas monopiles in soft clay may experience significant degradation. Carswell et al. [54] suggested that further analysis is required for medium clays, where load magnitude strongly influences estimates of natural frequency and permanent rotation.

Many studies have examined predictions and observations of the long-term performance of monopiles (see e.g. LeBlanc et al. [55], Tasan et al. [56], Choi et al. [57] and Klinkvort et al. [58]). LeBlanc et al. [55] considered the effect of accumulated rotation and stiffness changes on small-scale stiff piles, after longterm cyclic loading was carried out lasting between 8000 and 60,000 load cycles. Depina et al. [59] undertook a probabilistic assessment of the long-term performance of offshore wind turbine monopile foundations in dense sand of spatially varying stiffness, and used a 3D FE pile-soil model coupled with a stiffness degradation material model to simulate foundation response under long-term cyclic loading. The statistics associated with the monopile displacements, rotations, and bending moments demonstrated the influence of monopile embedment length and number of lateral loading cycles on the long-term probabilistic response of monopile foundations. Barari et al. [60] proposed a new design framework based on performance measures for cyclic horizontally loaded monopile foundations located in saturated and dry dense sand, by considering pile deformations and pore pressure accumulation effects. Through 3D numerical studies, Barari et al. [60] found that no differences were discernible between power law and logarithmic approaches in terms of describing accumulated deformations at low numbers of load cycles $(<$ 1000), whilst the logarithmic law was less able to describe the accumulation response at high numbers of cycles ( $>10,000$ cycles). An increase in magnitude of the cyclic loads caused a linear increase in accumulated rotation. Barari et al. [60] concluded that few load cycles with higher load levels are the main concerns in accumulation of pile rotation rather than thousands of load cycles of low amplitudes.

Offshore wind turbines are believed to experience about 10,000,000 load cycles during their lifespan [61]. For a monopile under cyclic loading with so many load cycles, it is possible that the foundation stiffness will change over the lifespan, affecting the natural frequency of the wind turbine-pile-soil system and its response [62]. Ma et al. [62] considered the characteristics of pile-soil interaction under long-term cyclic lateral loading observed in well-controlled laboratory model tests by modelling them using a 3D FE model 
of the long-term performance of large diameter, offshore wind turbine monopiles in sand. Ma et al. found that deflection and rotation of the pile head under long-term cyclic loading were notably greater than when the long-term effect was neglected.

Considering the large number of load cycles experienced by offshore wind turbines over their service lives, the lack of guidance in practice, and the limited understanding of the effect of long-term cyclic loading on monopiles, further research is needed on the lateral response of monopiles under cyclic loading when the number of load cycles is very large.

\section{Monopile behaviour under combined axial and lateral loading}

Research investigations have considered interaction effects of a monopile under combined axial and lateral loading for different soil types. Karthigeyan et al. $[63,64]$ carried out numerical simulations of piles, and found that axial loading on a pile located in sandy soil increased the pile's lateral load-carrying capacity by about $40 \%$ (depending on the magnitude of axial loading), but caused marginal reductions in clayey soils. Haiderali et al. [42] investigated the axial and lateral response of monopiles installed in undrained clays of varying shear strength and stiffness using 3D FE analysis. They found that with the exception of extremely high axial loads bordering on monopile axial capacities, variation in axial load does not have a significant effect on ultimate lateral capacity and lateral displacement of monopiles. Mu et al. [65] conducted a series of model tests to investigate the influence of vertical loads on the lateral response of a monopile in sandy soil. Mu et al. [65] found that the presence of a vertical load improves the lateral behaviour of the monopile. The influence of vertical load on the $p-y$ curve around the monopile was also examined, to inform better monopile design. $\mathrm{Mu}$ et al. [65] proposed several equations to evaluate the degree of this improvement, and hence calculate the lateral responses of the monopile based on the traditional design method. The coupled effect of vertical loads and lateral loads on a monopile under different soil conditions remains not fully understood, and more research is required in the future.

\subsubsection{Modelling of monopile-soil interaction}

For foundations of offshore wind turbines with jacket, tripod, and lattice support structures, which involve the interaction of piles with seabed soil, a suitable pile foundation model needs to be selected to examine pile flexibility as part of the design process. A monopile is a large-diameter pipe pile from a geotechnical perspective, and so proper foundation modelling is critical for the design of offshore wind turbine monopile foundations. Such foundations experience large moments due to the large lateral loads exerted by wind and waves on the slender turbine towers. For response analysis of the structure, it is necessary to model the interaction between the monopile and seabed in order to consider actual soil conditions. 
In typical pile response analysis, soil resistance is conventionally modelled using discrete uncoupled springs attached to the element nodes. The pile is designed to sustain axial and horizontal static or cyclic loadings, and its deformation should meet structure serviceability requirements. For pile axial load-settlement response, the soil spring behaviour is described by nonlinear $t-z$ curves $(t$ is the mobilised shaft friction and $z$ is the local pile deflection). For lateral load-deflection response, the soil spring behaviour is described by nonlinear $p-y$ curves, as shown in Fig. 8. At the time of writing, several empirical and theoretical approaches are available to construct $t-z$ curves and $p-y$ curves. For design of offshore structures, API [40] provides a procedure for constructing these curves.

In the dynamic analysis of an offshore wind turbine with a monopile foundation, the large lateral force on the monopile and the large moment at the tower base make the lateral response of foundation critical. Approaches for foundation modelling include the traditional $p-y$ curve and more recent FE methods.

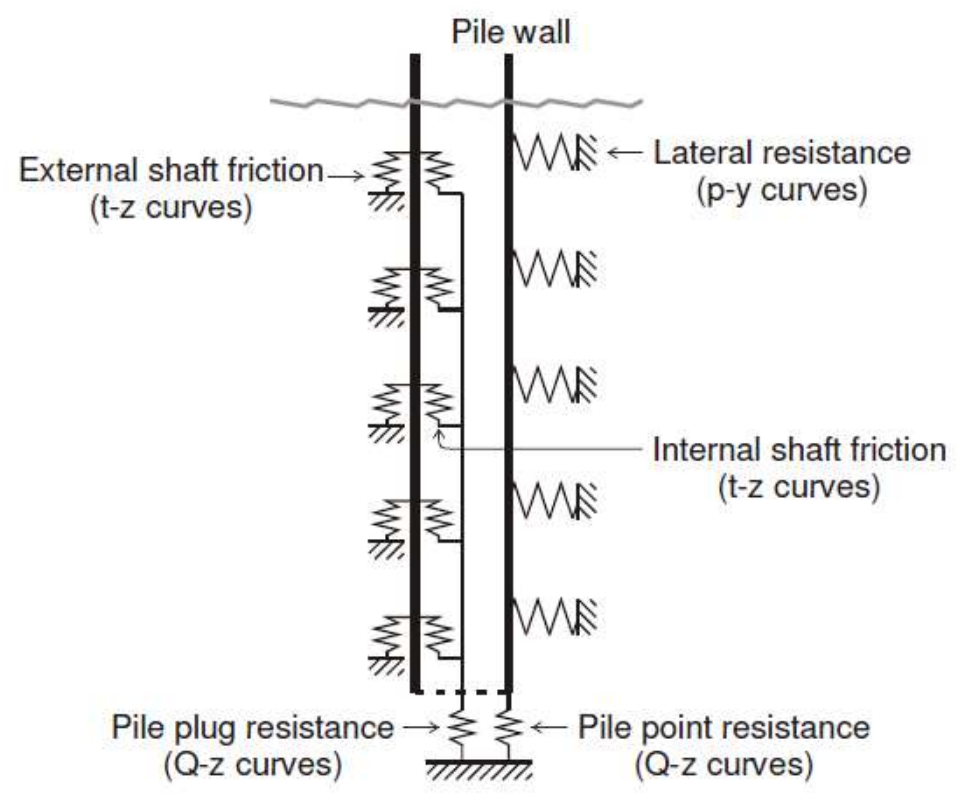

Fig. 8. Spring model of pile-soil interaction (Reproduced from Zaaijer (2002)) [66]

\section{Monopile foundation modelling based on $p-y$ curve method}

The lateral soil resistance - lateral deflection $(p-y)$ curve method is commonly used for the design of pile foundations of offshore structures. In practice, the pile is designed to sustain lateral static or cyclic loads and should not fail by overloading. Due to interaction between the pile and soil, the lateral resistance of soil near the surface of the seabed is important for pile design. Deformation of the pile under lateral loads thus relates to soil resistance, given that the soil behaves as plastic material. By means of a series of laboratory tests on soil samples, $p-y$ curves can be constructed to facilitate analysis of the pile response [40]. 
Furthermore, API [40] recommend the construction of ultimate lateral bearing capacity curves and $p-y$ curves for monopiles in soft clay and stiff clay. Fig.9 shows the typical shape of $p-y$ curves for soft clay under static and cyclic loadings according to Matlock [67] .

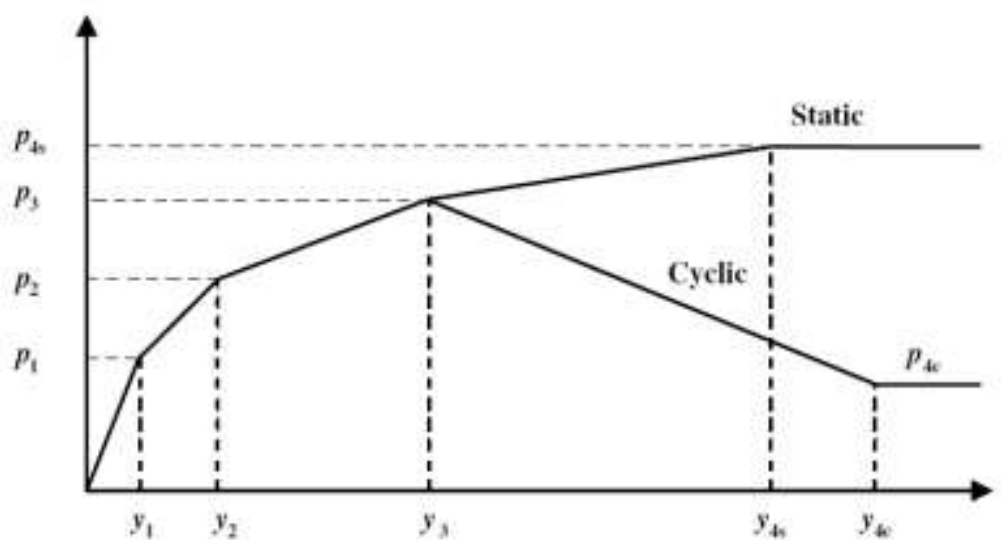

Fig. 9. Typical shape of horizontal load $p$ and displacement $y$ in a $p-y$ curve for soft clay under static and cyclic loading according to Matlock [67]

Studies using the $p-y$ curve method for foundation modelling have been conducted by Zaaijer et al. [68], Van der Tempel [69], Bush and Manuel [70], and Jung et al. [71]. Zaaijer et al. [68] applied different kinds of pile foundation models to investigate the sensitivity of the natural frequency of the support structures of offshore wind turbine to choice of pile foundation model. In this study, Zaaijer et al. [68] investigated four kinds of pile foundation model which they termed "finite element model with distributed springs for lateral and axial soil stiffness", "effective fixity length of the foundation pile", "stiffness matrix of foundation behaviour at mudline", and "uncoupled lateral, axial and rotational springs at mudline" (Fig.10). Two approaches for obtaining the lateral and rotational spring stiffness were utilised in the "uncoupled spring" model. Zaaijer et al. [68] concluded that the stiffness matrix model is more appropriate in modelling the pile foundation flexibility, due to reduction in complexity with acceptable loss of accuracy, whereas the uncoupled spring model and effective fixity model were not recommended for use in practice. Van der Tempel [69] coupled a similar stiffness matrix model with the nonlinear $p$-y model to analyse the pile foundation of an offshore wind turbine support structure. Jung et al. [71] used a coupled spring model with $p-y$ curves to study the structural response of a $5 \mathrm{MW}$ offshore wind turbine tower. The tilt of the pile head predicted from the $p-y$ curve method was significantly smaller than from the FE study, indicating that the $p-y$ curve method is non-conservative. 


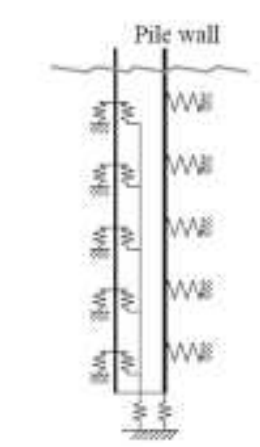

Reference Distributed springs
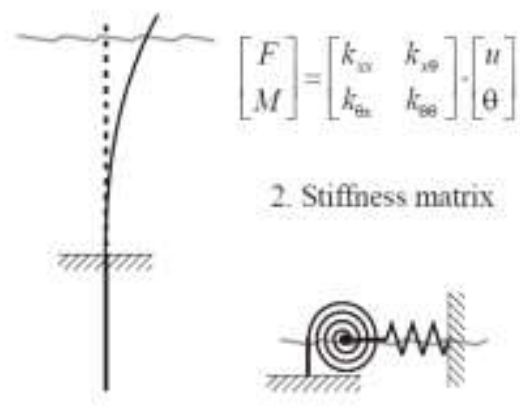

2. Stiffness matrix

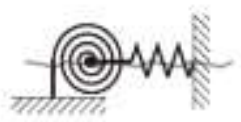

1. Fixity length

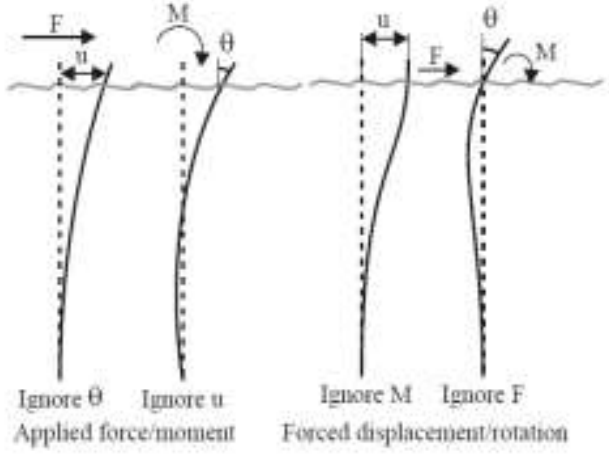

3. a Force method 3.b Displacement method

Fig.10. Foundation models (Reproduced from Zaaijer (2002)) [68]

Although similar to piles used at the bottom of jacket, tripod, or lattice structures, the monopile has a very large diameter, which greatly affects its behaviour. Application of the $p-y$ curve method may be reasonable for a traditional pile foundation, but there are many limitations in using conventional models for offshore wind turbine foundations [72]. Hearn and Edgers [73] concluded that the $p-y$ curve method overestimated horizontal resistance compared to FE analysis in studies of the lateral resistance of a monopile in dense sand. Achmus and Abdel-Rahman [74] also reported that the $p-y$ curve method is not applicable to determining the rotation and horizontal displacement of a large-diameter, offshore wind turbine monopile.

\section{FEM-based monopile foundation modelling}

Finite element modelling of the foundation/soil interaction of monopile has been conducted by Lesny and Wiemann [75], Lesny et al. [76], Sørensen et al. [77], Hearn [78], Hearn and Edgers [73], Achmus and Abdel-Rahman [74], and Jung et al. [71]. For FE analysis, commercial software is used to model the soil and monopile interaction. Soil and pile material, monopile and soil interface, and boundary non-linearity should be considered. FE simulations of load-displacement curves are then converted to an equivalent coupled spring. Validation of FE analyses have been undertaken by Achmus et al. [79] and Jung et al. [71] for a monopile in sand, and by Jung et al. [71] for a monopile in clay.

Lesny and Wiemann [75] compared results from FE analysis of monopile behaviour against results from a standard $p-y$ method. They found that the $p-y$ method overestimated soil stiffness at large depth. Based on their numerical study, Lesny and Weimann proposed a modified $p-y$ method that provided better design of large diameter monopiles. For monopile foundation FE analysis, the pile was assumed to act as linear elastic material, and contact between monopile and soil modelled by contact elements with finite sliding, based on the Coulomb friction law. Soil material non-linearity was represented by an elasto-plastic constitutive 
model with Mohr-Coulomb failure criterion and an oedometric modulus that was assumed to increase parabolically. Lesny et al. [76] also applied this same FE model when dealing with the pile and soil material behaviour, and the monopile/soil interface non-linearity in the FE analysis.

Jung et al. [71] studied the effect of monopile foundation modelling on the structural response of a 5 MW offshore wind turbine tower, including wind aerodynamics on the turbine, and compared results obtained using $p-y$ curves and FE-based foundation models. Jung et al. [71] concluded that it is very important to consider foundation flexibility in order to obtain accurate estimates of wind turbine behaviour. Although there was a slight difference in estimates of the base moment by the two foundation analysis techniques, the FE model predicted a much larger tilt in the pile head. Jung et al. [71] therefore suggested that FE modelling should be applied to offshore wind turbine foundations that might experience serviceability issues caused by significant tilt.

Considering the difference in behaviour of monopile and traditional pile foundations, it is recommended that the traditional $p-y$ curve method be modified to incorporate the specific behaviour of a large-diameter monopile. Moreover, FEM-based models should be applied which consider practical soil properties and monopile behaviour in order to achieve more reliable analysis of monopile-soil interaction.

\subsubsection{Scour around monopile foundations}

An important engineering challenge is posed by scour development around a monopile foundation. Scour is a combination of hydrodynamic and geotechnical processes resulting from fluid-structure-soil interaction [80]. Water-induced transport of sediment away from the monopile alters the capacity of local soil sediments and causes local scour holes to develop when the near-bed shear stress exceeds the critical shear stress at which sediment starts to move [81]. Scour influences the bearing capacity of the monopile foundation, the dynamic behaviour of the offshore wind turbine system, and may even cause structural instability. Studies of scour around monopiles have primarily focused on scour depth prediction, design of scour protection schemes, and assessment of the structural response of a monopile to the altered local bed morphology once scour occurs. A static design formula for calculating the stone size of scour protection for a monopile subject to combined waves and currents was derived by De Vos et al. [82] based on laboratory test data. Sumer et al. [83] and Zanke et al. [84] provide formulae for evaluating the scour depth around a pile under different flow conditions. Matutano et al. [85] analysed these methods in the context of the design of medium and large diameter monopile foundations. They reported a need for revised design formulae in terms of environmental parameters in order to determine the extent of scour protection as a function of wave conditions in transitional water depths. Noting that DNVGL and ISO recommend use of the most extreme local scour depth as the design scour depth, which is a conservative approach, Sørensen 
and Ibsen [81] proposed an adaptive scour design approach to illustrate the potential savings gained by considering the variation of scour depth as a function of sea state during monopile design. Pang et al. [86] proposed an approximate approach for predicting the scour depth around a monopile using a numerical scour model. The method follows the typical approach to numerical prediction of scour: first, turbulent flow around the monopile was simulated; bed parameters were determined from the results; and finally model equations were solved for sediment transport and bed morphological evolution. It should be noted that Pang et al. [85] reduced the computational cost by applying an objective function and mesh optimiser to guide the bed morphology to the equilibrium scour depth. Given the dependence of scour on soil conditions and the uncertainty inherent in scour development around a monopile in cohesive and non-uniform soils, Harris et al. [80] provide a review based on contemporary evidence from field and laboratory measurements of the scour potential of cohesive soils. Harris et al. considered soil erodibility, scour in cohesive soils and clays, erosion testing, abrasion, cyclic loading, and observational evidence on the time evolution of scour holes. They presented field data from offshore wind turbine monopile foundations which indicated that existing methods for predicting scour in cohesive material could under-predict scour depth in non-uniform soils.

Qi and Gao [87] conducted an experimental study of local-scour and pore-pressure responses around a large-diameter monopile in combined waves and current, using a specially designed flow-structure-soil interaction flume. Based on the measured scour depth and pore pressure around the model pile, Qi and Gao [87] found that wave-current interaction had a substantial effect on the time-development of local scour and the resulting equilibrium scour depth. Prendergast et al. [88] tested the effect of scour on the natural frequency of a laboratory-scale offshore wind turbine monopile using numerical and experimental methods. Soil stiffness profiles were developed corresponding to loose, medium dense, and very dense sand. Prendergast et al. [88] concluded that wind turbines founded in loose sand would exhibit the largest relative reductions in natural frequency resulting from scour.

Further research is needed into scour around wind turbine monopile foundations in order to ascertain scour development when soil conditions are complicated and non-uniform, and under different combinations of waves and currents, including tsunamis.

\subsection{Geotechnical issues concerning suction bucket foundations}

Bucket foundations are extensively used for offshore oil and gas platforms. Bucket foundations can also be directly connected to the wind turbine tower (such as monopod, Fig.11(a) ) or form the base foundation of fixed jacket or tripod support structures (such as tripod, as shown in Fig.11(b)) or tension leg platform systems for floating wind turbines (Fig.2 and Fig.3). The first offshore wind turbine with a suction bucket 
foundation was installed in 2003 in Denmark, followed by a prototype monopod suction caisson at Horns Rev 2 Offshore Wind Farm in 2009 also in Denmark. In 2010, the first offshore wind turbine to have a large-scale top-bearing bucket foundation was installed in China [89]. Bucket foundations experience large vertical loads from the self-weight of the structures they support, horizontal loads from wind and waves, and base moments (produced by the horizontal loads). Loadings on bucket foundations of offshore wind turbines are composed of substantial lateral forces and overturning moments, and relatively low vertical loads, unlike corresponding loadings on bucket foundations of offshore platforms. Bucket foundations for offshore wind turbine support structures must therefore be designed specifically for such loading conditions. In the case of a bucket foundation of a TLP floating wind turbine system, the pullout capacity and longterm behaviour of the bucket under sustained and cyclic loading scenarios must be considered.

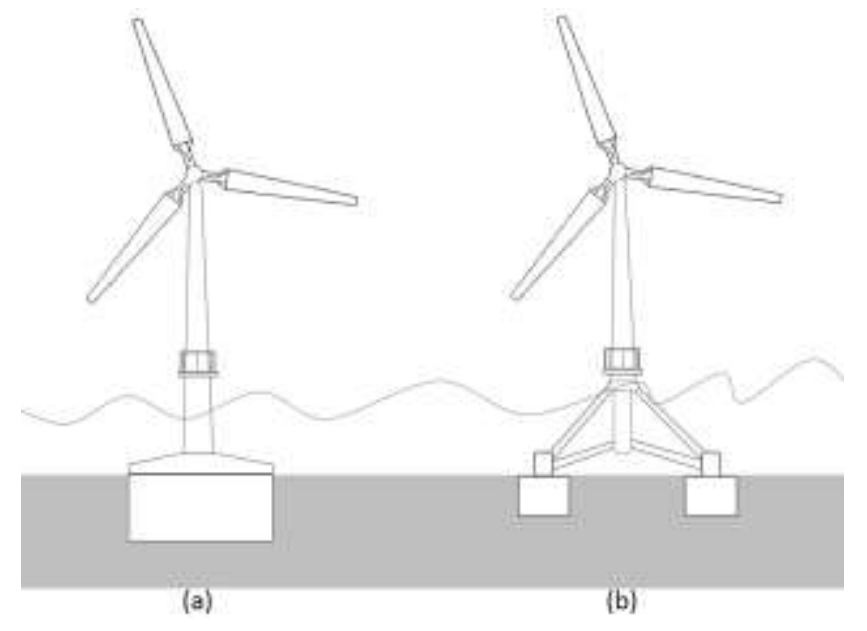

Fig.11. Caisson foundations for a wind turbine: (a) monopod, and (b) tripod/tetrapod(Reproduced from Houlsby et al. (2005))[90]

Studies of bucket foundations have tended to concentrate on bearing capacities under monotonic loading and cyclic loading, the aim being to provide a suitable design methodology [79,89,91-119]. Installation processes for bucket foundations in different soils have also been considered [99,103,120-125].

\subsubsection{Capacity and behaviour of bucket foundations}

A large number of studies have investigated the bearing capacity of bucket foundations through analytical methods, numerical analysis, laboratory measurements, and field tests [79,89,91-119]. These studies examined the bearing capacity of bucket foundations under monotonic loading and cyclic loading in clay, sand, and layered soils. Vertical, horizontal, moment, and combined loading conditions were considered, along with eccentric and cyclic horizontal loading conditions. The resulting understanding of bearing behaviour and soil failure mechanisms led to development of bearing capacity equations applicable to 
determining the bucket capacity for foundation design. Moreover, horizontal load-displacement and moment-rotation relationships were investigated for the serviceability assessment of foundation.

\section{Capacity of bucket foundations under monotonic loading}

The earliest numerical studies on the vertical bearing capacity of bucket foundations in clay assumed the bucket foundation was either a skirted strip foundation in 2D FE analyses (see e.g. Bransby and Randolph [91,92], Yun and Bransby [93,94], Gourvenec [95], and Bransby and Yun [96]), or an equivalent surface circular foundation in 3D FE analyses without considering foundation embedment (see e.g. Tani and Craig [97], and Bransby and Randolph [91]). Hung and Kim [98] conducted 3D numerical analyses of bucket foundations in normally consolidated clay to examine the influence of the skirt length, and proposed equations for calculating the vertical and horizontal bearing capacities of bucket foundations. Laboratory model experiments and field tests were also undertaken to investigate the vertical bearing behaviour of bucket foundations in clay (see e.g. Houlsby et al. [99], and Villalobos et al. [100]). Wang et al. [101] investigated the behaviour of an offshore wind turbine bucket foundation under eccentric horizontal loading in soft clay, and established a formula for calculating the eccentric horizontal bearing capacity. Using a combination of experiments and numerical analyses, Barari and Ibsen [102] studied the response of bucket foundations located in Yoldia clay to moment loading, and presented yield loci describing load combinations at failure.

The bearing behaviour of bucket foundations in sand under monotonic and combined loading scenarios has been studied by many researchers using numerical analysis, laboratory tests, and field tests [99,103-110]. For example, Barari et al. [111] conducted a series of experimental tests and numerical simulations to estimate the vertical capacity of bucket foundations in sand. Empirical depth factors were determined for dense, medium dense, and loose sands, and it was found that the bearing capacity increased linearly with embedment depth. Park et al. [112] proposed a series of equations for calculating the bearing capacity of bucket foundations in sand, and recommended combined shape-depth factors for calculating the shaft bearing capacity of a bucket foundation. Bagheri et al. [113] recently carried out an analysis of offshore wind turbine bucket foundations, and investigated the bearing behaviour of the bucket and the response of soil supporting the bucket in dense and medium dense sandy soils subjected to static horizontal loading. Dimensionless horizontal load-displacement and overturning moment-rotation relationships were derived using a power law. Good agreement was obtained between the numerical results and the straight lines obtained from the power law until threshold values of horizontal load and overturning moment is reached.

For bucket foundations in layered soil conditions such as soil overlaying clay, the earliest studies focused on the bearing behaviour of shallow surface strip or circular foundation on layered soil. More recent studies 
have considered the practical bucket geometry and effect of the embedment depth. Park et al. [114] performed a series of axisymmetric FE analyses to study the load transfer mechanism and predict the vertical bearing capacity of bucket foundations in sand overlying clay profiles. By examining the effects of soil condition, aspect ratio, and bucket tip-to-clay depth, equations were proposed for predicting vertical bearing capacity.

\section{Capacity of bucket foundations under cyclic loading and earthquake loading}

Turning to a bucket foundation under cyclic loading, the earliest study concerned the settlement of shallow foundations under cyclic loading due to storms, conducted by Andersen [115]. Watson and Randolph [116] tested a bucket foundation in the laboratory and derived fatigue contours for a few hundreds of cycles. Achmus et al. [79] used numerical simulation to study the effect of load magnitude, relative density, and embedment ratio on the behaviour of bucket foundations under cyclic loading. Foglia et al. [117] studied the response of bucket foundations on sand subjected to cyclic loading using macro-element modelling and physical experiments. The work led to the development of a simple cyclic macro-element model, which was able to capture the essential features of the drained behaviour of a bucket foundation under cyclic loading. The model for cyclic loading on the bucket foundation was based on a pre-existing plasticity model. Verification tests show that the cyclic loading model was able to capture typical features of the loaddisplacement response of a shallow foundation under cyclic loading, including the rate of decrease of displacement accumulation in progressive cycles, as well as shrinkage of the hysteresis loop area with number of cycles. Long-term accumulated horizontal and rotational displacements were investigated using the developed numerical model and physical experiments. In a recent study by Skau et al. [116] macroelements were used to model the cyclic behaviour of shallow bucket foundations using integrated time domain analyses, without compromising accuracy.

Gelagoti et al. [119] investigated the response of wind turbines founded on suction caissons subjected to monotonic lateral, cyclic, and earthquake loadings. Nonlinear 3D FE analyses considered the effect of soilfoundation interface conditions. Based on the monotonic and cyclic loading results, Gelagoti et al. [119] found that imperfect interface bonding could reduce moment capacity, and may lead to foundation detachment or even uplifting in the case of shallow embedded caissons. The response was also studied of a soil-foundation-wind turbine interacting system subjected to earthquake shaking, and the seismic behaviour evaluated on the basis of spectral characteristics. Gelaloti et al. [119] illustrated that system kinematics plays a crucial role in the response of large wind turbines under simultaneous environmental and seismic loading. Although the consequences are not instantly catastrophic, the accumulation of foundation rotation could lead to the turbine reaching serviceability limits during an early phase of operation. 
Wang et al. [89] conducted seismic centrifuge modelling to study the behaviour of suction bucket foundations for offshore wind turbines. Nine centrifuge tests were carried out for suction bucket foundations in both dry sand and saturated sandy soil to evaluate the effect of bucket geometry on seismic response by analysing recorded accelerations, pore water pressure ratios, and settlements of both the suction bucket foundation and soil surface. Wang et al. found that soil deposits with dry sand can provide sufficient strength to resist earthquake damage without significant settlement. However, for a bucket in saturated sand, the soil strength and stiffness reduced due to build-up of pore water pressure. In addition, the sand under and near the bucket exhibited a lower tendency to liquefaction compared to the free field; in this case, the soil was reinforced by the foundation.

\subsubsection{Installation behaviour of suction bucket foundations}

A suction bucket foundation undergoes a very different installation procedure compared to other types of foundation. Understanding of the soil mechanism during bucket installation by suction is important for suction bucket design, guidance on field installation, and serviceability assessment (noting that the installation process has a large impact on foundation capacity). Suction bucket foundations are applicable to a wide range of soil conditions, and so the installation of suction buckets/caissons in clay, sands and layered soil has been the subject of much investigation. Houlsby and Byrne [120] [121] derived equations for determining the bucket foundation penetration resistance to self-weight penetration and suction-assisted penetration in clay and sand, and discussed the relationship between suction and further penetration, limits to penetration that can be achieved by suction, and the effect of internal stiffeners. Houlsby and Byrne obtained close agreement between the calculated installation resistance and penetration with results from centrifuge tests. Owing to the complexity of the field soil types, speculations were provided concerning the installation of suction bucket foundations in different soil types, including layered soil (sand over clay material, and clay over sand material), stiff clay, coarse material, silts, and carbonate soils. Houlsby et al. [99] [103] conducted field tests on the suction bucket foundations of offshore wind turbines with monopod and tetrapod structures in clay and sand. The caisson installation process was monitored by recording simultaneously the axial loads and displacements. A $3.0 \mathrm{~m}$ caisson was used for the monopod tests, with constant vertical and horizontal loads representing the wind and current loads, and cyclic loading representing wave loads; scale effects were considered, except that of the wave period. Loading amplitudes were adjusted in order to examine foundation performance under operating and extreme conditions. A 1.5 $\mathrm{m}$ caisson was used for the tetrapod tests. The tests in clay were carried out at two locations in the same pit at Bothkennar, UK, whereas those in sand were undertaken at Luce Bay, UK. Zhou and Randolph [122] performed large deformation FE analyses to study the installation of a suction bucket in normally consolidated clay, and quantified the differences in bucket installation entirely by jacking and by a 
combination of self-weight and suction. Zhou and Randolph investigated the total installation force required, the soil displacement pattern, the amount of internal soil plug heave, and the total stress changes around the bucket wall. Based on bucket penetrations to depths 1 to 4 times the bucket diameter, Zhou and Randolph [122] found that the performance depended strongly on installation method, and that the soil flow pattern was very different for the two installation methods considered although the total installation force was similar. Due to the larger amount of displaced soil drawn into the bucket during suction installation than when jacking occurs, soil plug heave during suction installation was greater than that for jacking installation. Induced radial and total stresses around the bucket were found to be smaller for suction installation than for jacked installation during continuous penetration. Using centrifuge tests, Tran et al. [123] obtained data on penetration resistance for a suction bucket in sand with silt layers at different locations, and investigated effects of silt layer thickness and depth. Fig. 12 shows the installation resistance in sand overlain by a $1.0 \mathrm{~m}$ thick silt layer. Tran et al. [123] found that larger suction forces are required for penetration in silt overlying sand than for homogeneous sand. The suction pressure in sand with silt layers appeared to be independent of the position and thickness of the silt layer. An unstable soil plug, related to reduction in soil heave after suction, was observed in all soil profiles when silt layers were present. Ibsen and Thilsted [124] conducted numerical analyses to study the failure limits during suction bucket installation in soils composed of homogenous sand and layered sand. Ibsen and Thilsted [124] performed numerical flow analysis to determine the development of hydraulic gradients in response to applied suction, with results presented as simple closed form solutions useful for evaluation of suction thresholds against piping. The close form solutions were then compared against data from large-scale model tests performed at a natural seabed test site in Frederikshavn, Denmark. Lian et al. [125] carried out laboratory tests to investigate the interaction mechanisms of a bucket with saturated sand for both jacking and suction installation methods, and proposed a calculation method to determine required suction based on the test data.

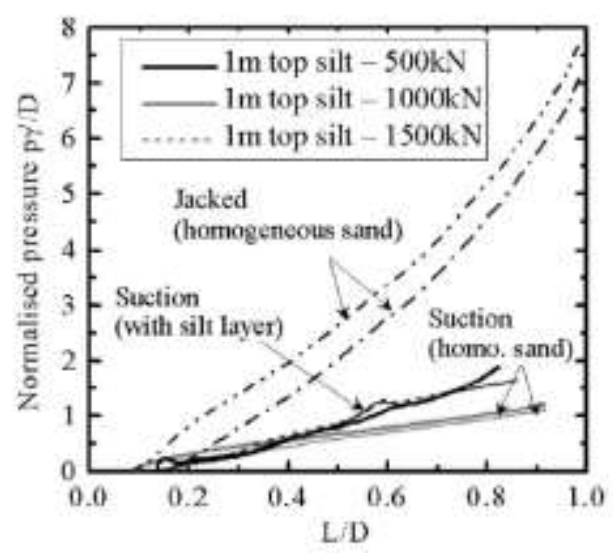

Fig. 12. Installation resistance in sand overlain by a 1.0m thick silt layer (Tran et al. [123]) 
Although many studies have examined bearing capacity and installation-related issues surrounding suction bucket foundations in different soil types, further research is needed into the effect of typical loading conditions on bucket foundation behaviour.

\subsection{Geotechnical issues concerning offshore anchors}

Section 2 previously introduced various anchorage types proposed for offshore mooring systems of floating structures. At the time of writing, floating wind turbines with anchored mooring systems can be classified as TLP (such as proposed by Blue H Technologies BV), spar type (such as Hywind Demo, Norway and Hywind Scotland by Statoil), and semi-submersible/tri-floater (such as the WindFloat prototype (WF1) off Portugal by Principle Power, and Fukushima-FORWARD Phase 1 in Japan). For TLP and spar type floating wind turbines, the anchor pullout capacity is critical in the design of the mooring system. As both offshore anchor foundations and floating offshore wind turbines are under simultaneous development, we next review research progress on evaluating plate anchor pullout capacity, the behaviour of plate anchors, drag anchors, OMNI-Max anchors under combined loading, prediction of drag anchor trajectories, and prediction of the keying processes of plate and OMNI-Max anchors.

Many studies [126-139] have considered the effect of anchor geometry on uplift capacity, the geometries including strip, rectangular, and circular anchors; anchor uplift capacity relates to the anchor response to loading normal to the bearing surface. However, the studies encountered problems from soil material nonlinearity, anchor-soil interface non-linearity, and large deformation of soil. These problems can be overcome in FE analysis by using a suitable soil model, interface model, and large deformation technique. Researchers [126-139] have examined the influence of anchor embedment depth, anchor-soil interface friction, breakaway conditions, anchor inclination angle, soil overburden pressure ratio, and soil profile. The uplift anchor capacity in undrained clay is usually expressed as the following function of undrained shear strength [129] :

$$
Q_{\mathrm{u}}=q_{\mathrm{u}} A=A N_{\mathrm{c}} S_{\mathrm{u}}
$$

where $Q_{\mathrm{u}}$ is anchor capacity, $q_{\mathrm{u}}$ is average pressure, $A$ is anchor area, $S_{\mathrm{u}}$ is undrained shear strength at embedment depth, and $N_{\mathrm{c}}$ is bearing capacity factor. In practice, the uplift bearing capacity factor $N_{\mathrm{c}}$ may be determined from plastic limit analysis $[126,129,130,135]$ or FEM simulation $[128,131-134,136-139] . N_{\mathrm{c}}$ is a function of embedment ratio, shape of flukes (i.e. strip, rectangular, square, or circular), overburden pressure ratio, and inclination angle. However, when either the embedment ratio or overburden ratio exceeds a certain limit, the bearing capacity factor becomes constant, indicating that the anchor is experiencing a deep localized failure mechanism [129]. For deeply embedded plate anchors, a typical value 
of $N_{\mathrm{c}}$ is between 9 and 15 [126]. DNVGL [127] suggests a value of 12.5 should be applied in computation of the fluke normal stress when the anchor fluke is at equilibrium. Anchor geometry is complicated, and so most plastic limit analyses and numerical studies are based on simplified anchor shapes, such as strip, rectangle, square or circle. Many investigations have examined anchor uplift bearing capacity factors in uniform soil and soil with linearly increasing shear strength, and anchor horizontal and rotational capacities (see e.g. Rowe and Davis [128], Merifield et al. [129,130], Song and Hu [131], Song et al. [132], Wang et al. [133], Yu et al. [134], Yu et al. [135], Chen et al. [136], Tho et al. [137] and Wu et al. [138,139]). Capacity factors were investigated by considering anchor plate inclination, soil properties, and plate geometry.

The behaviour of drag and plate anchors under combined vertical, horizontal, and rotational loadings has been studied by many authors (such as Bransby and O’Neill [140], O'Neill et al. [141], Elkhatib and Randolph [142], Elkhatib [143], Yang et al. [144], Cassidy et al. [145], Wei et al. [146], Liu et al. [147], and $\mathrm{Wu}$ et al. $[138,139])$, the aim being to estimate anchor failure loading under combined loadings. Yield envelopes are used to characterise the anchor behaviour under such combined loadings. These envelopes could also be used to predict the drag anchor trajectory and the keying process of the plate anchor.

Although many studies have considered anchor capacity and trajectory, further work is nevertheless required on more rigorous trajectory and keying process prediction methods that consider practical anchor geometries and soil conditions, and anchor behaviour under long-term cyclic loading comprising large numbers of load cycles (especially for floating wind turbines). Given that offshore anchors are essential for wind farms in deep water, further research effort should be directed towards whole system stability (encompassing integrated anchors, mooring systems, and floating wind turbines under extreme environmental conditions), and more accurate predictions of drag anchor trajectories and keying processes of plate anchors.

\subsection{Structural issues concerning offshore wind turbine foundations}

\subsubsection{Structure capacity and response under environmental loads}

Structural responses of offshore support structures under uncoupled or combined wind and wave conditions determined from a given environmental model or measured data are reported by Seidel et al. [148], Agarwal and Manuel [149], Jensen et al. [150], Haselbach et al. [151], Mardfekri and Gardoni [152], and Saha et al. [153]. The foregoing works primarily concentrated on dynamic time history simulations of support structures in the elastic or operational range of response. Wei et al. [154] evaluated the ultimate structural capacity of offshore monopile support structures subjected to non-proportional environmental wind and 
wave load patterns for increasing wave height and wind-wave combined loading using a risk analysis methodology developed for OWTs under extreme loadings. Wei et al. [154] were then able to perform structural reliability analyses of monopile-supported offshore wind turbines using probabilistic models for site environmental conditions. Structural reliability analysis depends on dynamic analysis that is particularly time consuming when evaluating the dynamic response. Kim and Lee [155] proposed a novel approach to reliability analysis based on static response and a factor accounting for dynamic amplification, which greatly reduced the computational cost of dynamic analysis underpinning structural reliability analysis. Kim and Lee demonstrated their approach by application to OWT and jacket-type support structures under extreme wind and ocean wave loads. Recently, Jiang et al. [156] have provided a detailed overview of structural reliability analysis of wind turbines. Ziegler et al. [157] developed an efficient frequency-domain method for sensitivity analysis of wave-induced fatigue loads on offshore wind turbine monopile foundations. The influence of site parameters like water depth, soil stiffness, wave height, and wave period, could then be explored through local and global sensitivity studies and probabilistic assessment. Chew et al. [158] proposed an analytical gradient-based method to solve the highly-constrained, nonconvex and nonlinear nature of design optimisation of offshore wind turbine support structures under fatigue and extreme loads. Chew et al. [158] verified the method through a case study of the optimisation of two different jacket models, and found that the analytical method was reliable, consistently efficient, and more accurate than the conventional finite-difference approach. Ruiter and Zee [159] presented a sequential approach for analysing sensitivity of water flow-induced loads to support structure motion, and compared the computational performance of the sequential method against the traditional one using reduced model. The disregarded water flow loads in traditional reduced model were found to contribute significantly to the fatigue damage and maximum stresses under extreme loads [159]. The new sequential method was reasonably efficient, requiring $80 \%$ more calculation time than the traditional method [159]. Shi et al. [160] analysed dynamic ice-structure interactions of an offshore wind turbine monopile in drifting ice under parked and operating scenarios using numerical simulations. Lin et al. [161] employed computational fluid dynamics to conduct a hydrodynamic simulation of wave run-up elevations and wave loads on three types of wind turbine foundation.

For the foundations of offshore wind turbine, structural reliability depends on proper analysis of the effect of complex loads on the structure accounting for environmental site conditions, etc. Such numerical studies require efficient, reliable numerical models for calculating site-specific wave-, wind-, current-, and iceinduced loads on the structure of foundations.

\subsubsection{Fatigue analysis}


Monopile, tripod, jacket, and tripod support structures are potentially susceptible to fatigue damage that could then jeopardize the entire offshore wind turbine system. The fatigue load magnitude and number of load cycles considered in the design of OWTs are both significantly higher than for offshore oil and gas platforms. Fatigue analyses and buckling checks form important constituents of OWT foundation design [13]. The present design of OWT support structures with respect to fatigue usually involves dynamic analysis in the time domain, based on fatigue loads extracted directly from load or stress time histories by means of the rainflow-counting method. Alternatively, spectral fatigue damage analysis can be performed in the frequency domain [162]. Argyriadis and Klose [163] conducted detailed fatigue analysis of the tubular nodes of a jacket structure using loads derived from the integrated analysis of the wind turbine jacket support structure. Fatigue damage was determined from hot spot stresses in combination with related S-N curves. Yeter et al. [164] carried out a fatigue damage assessment of an OWT tripod structure under combined wave and wind loading, using FE for the coupled dynamic analysis in the frequency domain and modelling welded tubular joints by shell finite elements. Yeter et al. [165] then examined the fatigue reliability of the OWT support structure using a limit state function based on the S-N approach including uncertainties related to the structural response, induced load, material properties, and fatigue life prediction method. Yeter et al. [162] evaluated the performance of several spectral fatigue damage models in assessing the welded tubular joint of an offshore wind turbine tripod support structure. Using frequency domain analysis, Long and Moe [166] were able to dimension lattice-type OWT towers that met fatigue criteria during the preliminary design stage. Long and Moe [166] concluded that the resulting lattice-type structure required only half as much material as its tubular counterpart. Li et al. [167] conducted a study on shortterm fatigue damage at the tower base of a spar-type floating wind turbine. Realistic environment conditions provided loads and structural stresses at the tower bases, after which the cumulative fatigue damage was calculated via the rainflow-counting method and Miner's rule. Fig. 13 illustrates the short-term fatigue damage analysis procedure for the tower base. Li et al. [167] found that wind- and wave-induced loads influence axial stress at the tower base in a decoupled way, and that 


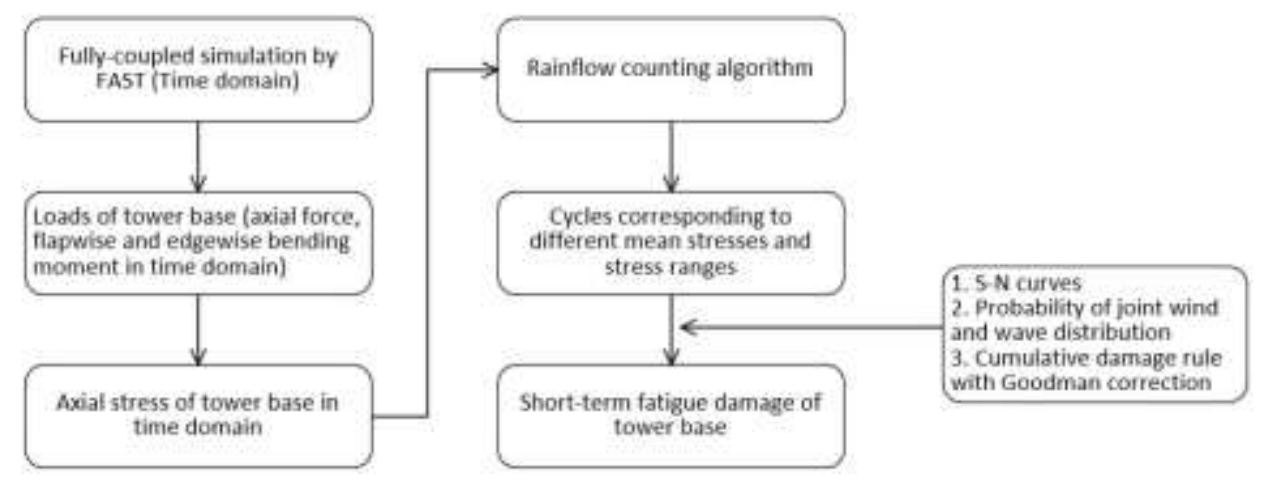

Fig.13. Short-term fatigue damage analysis procedure for tower base (Reproduced from Li et al.(2017) )

wave-induced fatigue damage was greater than wind-induced fatigue damage. Under operating conditions at rated wind speed, the predicted fatigue damage at the tower base is greatest when joint probability of wind and wave is included in the calculation. Schafhirt et al. [168] concluded that variations in soil properties needed to be considered in order to obtain more accurate assessment of the fatigue performance of offshore monopile wind turbines.

In short, although many studies have considered fatigue damage to OWT support structures, there remains a need for more accurate prediction of the fatigue lifetime, and for further development of the fatigue analysis method including appropriate soil-foundation interface conditions and integrated analysis of the OWT system.

\section{Summary}

This paper has provided an overview of recent developments in offshore wind turbine foundations, focusing on geotechnical and structural research issues posed by typical foundations used in fixed and floating offshore wind turbine installations, including buckets, monopiles, and anchors.

In the near future offshore wind towers will increase significantly in size and capacity, driven by the high demand for marine renewable energy. Design, fabrication, transportation, and installation of offshore wind turbine structures are of major concern to the offshore wind energy industry, noting the complexity of the ocean environment. Offshore wind turbine foundations are key to structural integrity and serviceability, and have been the subject of substantial recent research and development. However, many research questions remain at best partially answered, particularly regarding the foundations of large-scale offshore wind farms and floating offshore wind turbine installations. A reliable, comprehensive industry code for the design of 
offshore wind turbine foundations is urgently required, based on a full understanding of foundation behaviour under loading conditions specific to offshore wind turbines. Further research into numerical techniques for the integrated foundation-wind turbine response to offshore environmental loads is necessary to achieve reliable analysis of structural response. Field monitoring and laboratory test measurements are important prerequisites for improved understanding of the behaviour of offshore wind turbine foundations and for validation of numerical models used in design, and hence are vital for the future development of offshore wind technology.

Our recommendations are as follows:

(1) Design codes for offshore wind turbine foundations should be developed that account for actual conditions encountered by offshore wind turbines (such as cyclic loading and the pile size), and not purely based on codes for offshore oil and gas platforms.

(2) More advanced numerical techniques should be developed that model the whole structure-foundationsoil system, incorporating foundation and soil interface conditions, soil properties, soil constitutive models and environmental wind, wave, current, and ice loads.

(3) Field monitoring and experimental measurement campaigns are required to provide further insight into the performance of offshore wind turbine foundations and to collect high quality archive data for validation of numerical models, particularly those models related to the foundation-soil interface and the integrated dynamic response analysis of the whole wind turbine system.

(4) In order for floating offshore wind turbine technology to reach its full potential in deep water applications, further research needs to focus on the geotechnical engineering of offshore anchors and hydrodynamics of mooring systems.

\section{Acknowledgements}

The authors gratefully acknowledge support from the Thousand Talents Program, the NSFC-RCUK (EPSRC Grant EP/R007632/1), and the National Natural Science Foundation of China (Grants 51761135012, 51809165, 51479114, and 11742021). We also thank several publishers which have given permission for copyrighted Figures to be reproduced herein. The paper is written in honour of Ian Bryden, our colleague and friend, who did so much to promote marine renewable energy.

\section{References}


[1] Timilsina GR, Cornelis van Kooten G, Narbel PA. Global wind power development: Economics and policies. Energy Policy. 2013;61:642-652.

[2] Tabassum A, Premalatha M, Abbasi T, Abbasi SA. Wind energy: Increasing deployment, rising environmental concerns. Renewable Sustainable Energy Rev. 2014;31:270-288.

[3] Perveen R, Kishor N, Mohanty SR. Off-shore wind farm development: Present status and challenges. Renewable Sustainable Energy Rev. 2014;29:780-792.

[4] EWEA. The economics of wind energy. 2009; http://www.ewea.org.

[5] Zhou X. The development of power system and power system technology in China. 1997.

[6] Esteban M, Leary D. Current developments and future prospects of offshore wind and ocean energy. Appl Energy. 2012;90(1):128-136.

[7] Morthorst PE, Kitzing L. Economics of building and operating offshore wind farms. 2016.

[8] Moné C, Hand M, Bolinger M, Rand J, Heimiller D, Ho J. 2015 Cost of wind energy review. ; Lawrence Berkeley National Lab. (LBNL), Berkeley, CA (United States);2017. LBNL-1007296; Other: ir:1007296 United States 10.2172/1366436 Other: ir:1007296 LBNL English.

[9] Şahin AD. Progress and recent trends in wind energy. Progress in Energy \& Combustion Science. 2004;30(5):501-543.

[10] Esteban MD, Diez JJ, López JS, Negro V. Why offshore wind energy? Renewable Energy. 2011;36(2):444-450.

[11] Angus McCrone EU, Virginia Sonntag-O'Brien, Ulf Moslener, Christine Grüning. Global trends in renewable energy investment 2013. 2013.

[12] Wu J, Wang ZX, Wang GQ. The key technologies and development of offshore wind farm in China. Renewable \& Sustainable Energy Reviews. 2014;34:453-462.

[13] O'Kelly B, Arshad M. Offshore wind turbine foundations: analysis and design. 2016.

[14] Castro-Santos L, Diaz-Casas V. Floating Offshore Wind Farms. Springer International Publishing; 2016.

[15] Gasch R, Twele J. Wind power plants: fundamentals, design, construction and operation. Springer Science \& Business Media; 2011.

[16] Miceli F. Offshore wind turbines foundation types. 2012; http://www.windfarmbop.com/tag/monopile/.

[17] Christensen ASaMM. Supply chain study on the Danish offshore wind industry. 2005.

[18] Kallehave D, Thilsted LB, Liingaard MA. Modification of the API p-y formulation of initial stiffness of sand. J Cell Physiol. 2012;205(2):211-217.

[19] Byrne BW, Mcadam R, Burd HJ, Houlsby GT, Martin CM, Beuckelaers WJAP, et al. PISA: New design methods for offshore wind turbine monopiles. Paper presented at: International Conference for Offshore Site Investigation and Geotechnics2017.

[20] Black D. $£ 300 \mathrm{~m}$ Blyth offshore wind farm test facility planned by Narec. 2013; http://www.thejournal.co.uk/news/north-east-news/300m-blyth-offshore-wind-farm-4410945.

[21] Wikipedia. List of offshore wind farms in the United Kingdom. https://en.wikipedia.org/wiki/North_Hoyle_Offshore_Wind_Farm.

[22] Wikipedia. Scroby sands. https://en.wikipedia.org/wiki/Scroby_Sands.

[23] Wikipedia. Kentish flats offshore wind farm. https://en.wikipedia.org/wiki/Kentish_Flats_Offshore_Wind_Farm.

[24] Tien D. Repowering plan for Sweden's first offshore wind farm. 2012; http://www.windpoweroffshore.com/article/1190778/repowering-plan-swedens-first-offshore-wind$\underline{\text { farm. }}$.

[25] Bagner R. The end is near for Yttre Stengrunden. 2015; http://news.vattenfall.com/en/article/end-nearyttre-stengrund.

[26] Wikipedia. List of offshore wind farms in Sweden. https://en.wikipedia.org/wiki/List_of_offshore_wind_farms_in_Sweden.

[27] Wikipedia. Arklow Bank wind park. https://en.wikipedia.org/wiki/Arklow_Bank_Wind_Park. 
[28] Wikipedia. List of offshore wind farms in the Netherlands. https://en.wikipedia.org/wiki/List_of_offshore_wind_farms_in_the_Netherlands\#cite_note-4cNLlely10.

[29] Wikipedia. Alpha Ventus offshore wind farm. https://en.wikipedia.org/wiki/Alpha_Ventus_Offshore_Wind_Farm.

[30] Nikolaos N. Deep water offshore wind technologies. University of Strathclyde, Glasgow. 2004.

[31] Thomsen K. Offshore wind: a comprehensive guide to successful offshore wind farm installation. Academic Press; 2014.

[32] Wikipedia. Beatrice wind farm. https://en.wikipedia.org/wiki/Beatrice_Wind_Farm.

[33] Wikipedia. List of offshore wind farms in Denmark. https://en.wikipedia.org/wiki/List_of_offshore_wind_farms_in_Denmark.

[34] Gao W, Li C, Ye Z. The current situation and latest research of deep-sea floating wind turbine. Eng Sci. 2014.

[35] Wikipedia. Floating wind turbine. https://en.wikipedia.org/wiki/Floating_wind_turbine.

[36] Wu X. Numerical modelling of behavior of drag anchors, National University of Singapore; 2017.

[37] Vryhof Anchors. Anchor manual 2015-The guide to anchoring. In: Global Maritime VA, ed. The Netherlands 2015.

[38] Yang M, Aubeny CP, Murff JD. Behavior of suction embedded plate anchors during keying process. Journal of Geotechnical \& Geoenvironmental Engineering. 2012;138(2):174-183.

[39] Lowmass AC. Installation and keying of follower embedded plate anchors. University of Western Australia; 2006.

[40] RP2A-WSD A. Recommended practice for planning, designing and constructing fixed offshore platforms-working stress design-. Paper presented at: Twenty-2000.

[41] Igoe D, Gavin K, O'Kelly B. Field tests using an instrumented model pipe pile in sand. Izvakadnauk Sssr Sermat. 2010;20(2):244\&ndash;268.

[42] Haiderali A, Cilingir U, Madabhushi G. Lateral and axial capacity of monopiles for offshore wind turbines. Indian Geotechnical Journal. 2013;43(3):181-194.

[43] Bisoi S, Haldar S. Dynamic analysis of offshore wind turbine in clay considering soil-monopile-tower interaction. Soil Dynamics and Earthquake Engineering. 2014;63:19-35.

[44] Gavin KG, O'Kelly BC. Effect of friction fatigue on pile capacity in dense sand. Journal of Geotechnical \& Geoenvironmental Engineering. 2007;133(1):63-71.

[45] Igoe DJP, Gavin KG, O'Kelly BC. Shaft capacity of open-ended piles in sand. Journal of Geotechnical and Geoenvironmental Engineering. 2011;137(10):903-913.

[46] DNV. Design of offshore wind turbine structures. Offshore Standard DNV-OS-J101. 2004.

[47] Achmus M, Kuo YS, Abdel-Rahman K. Behavior of monopile foundations under cyclic lateral load. Computers \& Geotechnics. 2009;36(5):725-735.

[48] Randolph MF. The response of flexible piles to lateral loading. Geotechnique. 1981;31(2):247-259.

[49] Broms BB. Lateral resistance of piles in cohesionless soils. Journal of the Soil Mechanics and Foundations Division. 1964;90(3):123-158.

[50] Matlock H, Reese LC. Generalized solutions for laterally loaded piles. Geotechnical Special Publication. 1960;127(118):1220-1248.

[51] Haiderali A, Madabhushi G. Three-dimensional finite element modelling of monopiles for offshore wind turbines. Paper presented at: World Congress on Advances in Civil, Environmental, and Materials Research2012.

[52] Ahmed SS, Hawlader B, Roy K. Finite Element Modeling of Large Diameter Monopiles in Dense Sand for Offshore Wind Turbine Foundations. Paper presented at: ASME 2015 34th International Conference on Ocean, Offshore and Arctic Engineering2015.

[53] Byrne BW, Mcadam R, Burd HJ, Houlsby GT, Martin CM, Zdravkovic L, et al. New design methods for large diameter piles under lateral loading for offshore wind applications. Paper presented at: International Symposium on Frontiers in Offshore Geotechnics2015. 
[54] Carswell W, Arwade SR, Degroot DJ, Myers AT. Natural frequency degradation and permanent accumulated rotation for offshore wind turbine monopiles in clay. Renewable Energy. 2016;97:319-330.

[55] Leblanc C, Houlsby GT, Byrne BW. Response of stiff piles in sand to long-term cyclic lateral loading. Géotechnique. 2010;60(2):79-90.

[56] Ta,San H, Savidis S. Behaviour of cyclic laterally loaded large diameter monopiles in saturated sand. 2000.

[57] Choi CH, Jang, Y. E., Lee, J., \& Cho, S.-D. A numerical approach for determination of lateral stiffness considering soil-foundation interaction in offshore wind energy system. Paper presented at: EWEA2012presentation, (2001), 3813.2012.

[58] Klinkvort RT, Leth CT, Hededal O. Centrifuge modelling of monopiles in dense sand at The Technical University of Denmark. Delft University of Technology \& Deltares. 2012.

[59] Depina I, Le TMH, Eiksund G, Benz T. Behavior of cyclically loaded monopile foundations for offshore wind turbines in heterogeneous sands. Computers \& Geotechnics. 2015;65:266-277.

[60] Barari A, Bagheri M, Rouainia M, Ibsen LB. Deformation mechanisms for offshore monopile foundations accounting for cyclic mobility effects. Soil Dynamics \& Earthquake Engineering. 2017;97:439-453.

[61] Schaumann P, Lochte - Holtgreven S, Steppeler S. Special fatigue aspects in support structures of offshore wind turbines. Materialwiss Werkstofftech. 2015;42(12):1075-1081.

[62] Ma H, Yang J, Chen L. Numerical analysis of the long-term performance of offshore wind turbines supported by monopiles. Ocean Eng. 2017;136:94-105.

[63] Karthigeyan S, Ramakrishna VVGST, Rajagopal K. Influence of vertical load on the lateral response of piles in sand. Computers \& Geotechnics. 2006;33(2):121-131.

[64] Karthigeyan S, Ramakrishna VVGST, Rajagopal K. Numerical Investigation of the Effect of Vertical Load on the Lateral Response of Piles. Journal of Geotechnical \& Geoenvironmental Engineering. 2007;133(5):512-521.

[65] Mu L, Kang X, Feng K, Huang M, Cao J. Influence of vertical loads on lateral behaviour of monopiles in sand. European Journal of Environmental \& Civil Engineering. 2017:1-16.

[66] Zaaijer M. Sensitivity analysis for foundations of offshore wind turbines. Section Wind Energy, TUDelft. 2002.

[67] Matlock H. Correlation for design of laterally loaded piles in soft clay. Paper presented at: Offshore Technology in Civil Engineering1970.

[68] Zaaijer M. Foundation models for the dynamic response of offshore wind turbines. Marine Renewable Energy Conference; 2002; Newcastle, UK.

[69] Van der Tempel J. Design of support structures for offshore wind turbines, Delft University of Technology; 2006.

[70] Bush E, Agarwal P, Manuel L. The influence of foundation modeling assumptions on long-term load prediction for offshore wind turbines [c55]. Paper presented at: International Conference on Offshore Mechanics and Arctic Engineering2008.

[71] Jung S, Kim SR, Patil A, Le CH. Effect of monopile foundation modeling on the structural response of a 5-MW offshore wind turbine tower. Ocean Eng. 2015;109:479-488.

[72] Structural NRCCoOWET, Safety O. Structural integrity of offshore wind turbines : oversight of design, fabrication, and installation. Transportation Research Board; 2011.

[73] Hearn EN, Edgers L. Finite element analysis of an offshore wind turbine monopile. Paper presented at: Geoflorida2010.

[74] Achmus M, Abdel-Rahman K. Design of piles for offshore wind energy foundations with respect to horizontal loading. Paper presented at: The Twenty-second International Offshore and Polar Engineering Conference2012.

[75] Lesny K, Wiemann J. Finite-element-modelling of large diameter monopiles for offshore wind energy converters. Proceedings. 2006:1-6. 
[76] Lesny K, Paikowsky SG, Gurbuz A. Scale effects in lateral load response of large diameter monopiles. Paper presented at: Geo-Denver2007.

[77] Sørensen SP, Brødbæk KT, Møller M. Evaluation of load-displacement relationships for largediameter piles. Report/thesis. 2009.

[78] Hearn E. Finite element analysis of an offshore wind turbine generator monopile foundation. Dissertations \& Theses - Gradworks. 2009;82(16):1462-1465.

[79] Achmus M, Akdag CT, Thieken K. Load-bearing behavior of suction bucket foundations in sand. Appl Ocean Res. 2013;43(5):157-165.

[80] Harris JM, Whitehouse RJS. Scour development around large-diameter monopiles in cohesive soils: evidence from the Field. Journal of Waterway Port Coastal \& Ocean Engineering. 2017;143(5).

[81] Sørensen SPH, Ibsen LB. Assessment of foundation design for offshore monopiles unprotected against scour. Ocean Eng. 2013;63(3):17-25.

[82] De Vos L, De Rouck J, Troch P, Frigaard P. Empirical design of scour protections around monopile foundations: Part 1: Static approach. Coastal Eng. 2011;58(6):540-553.

[83] Sumer BM, oslash, Freds, Oslash R, Christiansen N. Scour around vertical pile in waves. Journal of Waterway Port Coastal \& Ocean Engineering. 1992;118(118):15-31.

[84] Zanke UCE, Hsu TW, Roland A, Link O, Diab R. Equilibrium scour depths around piles in noncohesive sediments under currents and waves. Coastal Eng. 2011;58(10):986-991.

[85] Matutano C, Negro V, López-Gutiérrez JS, Esteban MD. Scour prediction and scour protections in offshore wind farms. Renewable Energy. 2013;57(3):358-365.

[86] Pang ALJ, Gullman-Strand J, Morgan N, Skote M, Lim SY. Determining Scour Depth for Offshore Structures Based on a Hydrodynamics and Optimisation Approach. Paper presented at: Offshore Technology Conference Asia2016.

[87] Qi WG, Gao FP. Physical modeling of local scour development around a large-diameter monopile in combined waves and current. Coastal Eng. 2014;83(83):72-81.

[88] Prendergast LJ, Gavin K, Doherty P. An investigation into the effect of scour on the natural frequency of an offshore wind turbine. Ocean Eng. 2015;101:1-11.

[89] Wang X, Yang X, Zeng X. Seismic centrifuge modelling of suction bucket foundation for offshore wind turbine. Renewable Energy. 2017;114.

[90] Houlsby GT, Ibsen LB, Byrne BW. Suction caissons for wind turbines. Gacassidy Frontiers in Offshore Geotechnics Isfog. 2005;10(6):1 - 6 .

[91] Fraser BM, Randolph MF. Combined loading of skirted foundations. Géotechnique. 1998;48(5):637655.

[92] Fraser BM, Randolph MF. The effect of embedment depth on the undrained response of skirted foundations to combined loading. Journal of the Japanese Geotechnical Society. 1999;39(4):19-33.

[93] Yun G, Bransby MF. The horizontal-moment capacity of embedded foundations in undrained so. Revue Canadienne De Géotechnique. 2007;44(4):409-424(416).

[94] Yun G, Bransby MF. The undrained vertical bearing capacity of skirted foundations. Soils \& Foundations. 2007;47(3):493-505.

[95] Gourvenec S. Effect of embedment on the undrained capacity of shallow foundations under general loading. Géotechnique. 2008;58(3):177-185.

[96] Yun GJ, Bransby MF. The undrained capacity of skirted strip foundations under combined loading. Géotechnique. 2009;59(2):115-125.

[97] Tani K, Craig W. Bearing capacity of circular foundations on soft clay of strength increasing with depth. Journal of the Japanese Geotechnical Society Soils \& Foundation. 1995;35(4):21-35.

[98] Le CH, Kim SR. Evaluation of vertical and horizontal bearing capacities of bucket foundations in clay. Ocean Eng. 2012;52(1):75-82.

[99] Houlsby GT, Kelly RB, Huxtable J, Byrne BW. Field trials of suction caissons in clay for offshore wind turbine foundations. Géotechnique. 2005;55(4):287-296. 
[100] Villalobos FA, Byrne BW, Houlsby GT. Model testing of suction caissons in clay subjected to vertical loading. Appl Ocean Res. 2010;32(4):414-424.

[101] Wang J, Qin M, Cai A, Zhang D. Analysis of bearing capacity behavior of single bucket foundation for offshore wind turbines under eccentric horizontal loading in soft clay. Paper presented at: World Non-Grid-Connected Wind Power and Energy Conference2010.

[102] Barari A, Ibsen LB. Undrained response of bucket foundations to moment loading. Appl Ocean Res. 2012;36(3):12-21.

[103] Houlsby GT, Kelly RB, Huxtable J, Byrne BW. Field trials of suction caissons in sand for offshore wind turbine foundations. Géotechnique. 2006;56(1):3-10.

[104] Bhattacharya S, Cox J, Lombardi D. Dynamics of offshore wind turbines on two types of foundations. Proc Inst Civ Eng Geotech Eng. 2013.

[105] Foglia A, Ibsen LB. A Similitude Theory for Bucket Foundations Under Monotonic Horizontal Load in Dense Sand. Geotechnical \& Geological Engineering. 2013;31(1):133-142.

[106] Zhu B, Byrne BW, Houlsby GT. Long-term lateral cyclic response of suction caisson foundations in sand. Journal of Geotechnical \& Geoenvironmental Engineering. 2013;139(1):73-83.

[107] Villalobos FA, Byrne BW, Houlsby GT. An experiment study of the drained capacity of suction caisson foundation under monotonic loading for offshore applications. Soil \& Foundation. 2009;49(3):477-488.

[108] Villalobos FA, Byrne BW, Houlsby GT. Moment loading of caissons installed in saturated sand. 2005.

[109] Houlsby G, Byrne B. Calculation procedures for installation of suction caissons. Report No OUEL2268/04, University of Oxford. 2004.

[110] Byrne BW, Houlsby GT, Kelly RB. A comparison of field and laboratory tests of caisson foundations in sand and clay. Géotechnique. 2006;56(9):págs. 617-626.

[111] Barari A, Ibsen LB, Ghalesari AT, Larsen KA. Embedment effects on the vertical bearing capacity of offshore bucket foundations on cohesionless soil. Int J Geomech. 2016;17(4).

[112] Park JS, Park D, Yoo JK. Vertical bearing capacity of bucket foundations in sand. Ocean Eng. 2016;121:453-461.

[113] Bagheri P, Su WS, Jin MK, Bagheri P, Su WS, Jin MK. Investigation of the load-bearing capacity of suction caissons used for offshore wind turbines. Appl Ocean Res. 2017;67:148-161.

[114] Park JS, Park D. Vertical bearing capacity of bucket foundation in sand overlying clay. Ocean Eng. 2017;134:62-76.

[115] Andersen KH. Bearing capacity under cyclic loading - offshore, along the coast, and on land. The 21st Bjerrum Lecture presented in Oslo, 23 November 2007. Canadian Geotechnical Journal. 2009;46(5):513-535.

[116] Watson P, Randolph M. A centrifuge study into cyclic loading of caisson foundations. Paper presented at: Proceedings of the International Conference Physical Modelling in Geotechnics, Hong Kong2006.

[117] Foglia A, Gottardi G, Govoni L, Ibsen LB. Modelling the drained response of bucket foundations for offshore wind turbines under general monotonic and cyclic loading. Appl Ocean Res. 2015;52:80-91.

[118] Skau KS, Grimstad G, Page AM, Eiksund GR, Jostad HP. A macro-element for integrated time domain analyses representing bucket foundations for offshore wind turbines. Marine Structures. 2018;59:158-178.

[119] Gelagoti FM, Kourkoulis RS, Lekkakis PC, Kaynia AM. Suction Caisson foundations for offshore wind turbines subjected to wave and earthquake loading: effect of soil-foundation interface. Géotechnique. 2015;64(3):171-185.

[120] Houlsby GT, Byrne BW. Design procedures for installation of suction caissons in clay and other materials. Proceedings of the Institution of Civil Engineers - Geotechnical Engineering. 2005;158(2):7582.

[121] Houlsby GT, Byrne BW. Design procedures for installation of suction caissons in sand. Geotechnical Engineering. 2005;158(158):135-144. 
[122] Zhou H, Randolph MF. Large deformation analysis of suction caisson installation in clay. Canadian Geotechnical Journal. 2006;43(12):1344-1357.

[123] Tran MN, Randolph MF, Airey DW. Installation of suction caissons in sand with silt layers. Journal of Geotechnical \& Geoenvironmental Engineering. 2007;133(10):1183-1191.

[124] Ibsen LB, Thilsted CL. Numerical study of piping limits for suction installation of offshore skirted foundations and anchors in layered sand. Balkema Publishers Aa. 2010.

[125] Lian J, Chen F, Wang H. Laboratory tests on soil-skirt interaction and penetration resistance of suction caissons during installation in sand. Ocean Eng. 2014;84(3):1-13.

[126] Kim BM. Upper bound analysis for drag anchors in soft clay. 2005.

[127] Det Norsk Veritas. Design and installation of fluke anchors In clay.

[128] Rowe RK, Davis EH. The behaviour of anchor plates in clay. Géotechnique. 1982;32(1):9-23.

[129] Merifield RS, Sloan SW, Yu HS. Stability of plate anchors in undrained clay. Géotechnique. 2001;51(2):141-153.

[130] Merifield RS, Lyamin AV, Sloan SW. Three-dimensional lower-bound solutions for the stability of plate anchors in sand. Journal of Geotechnical \& Geoenvironmental Engineering. 2003;129(3):243-253.

[131] Song Z, Hu Y. Vertical pullout behavior of plate anchors in uniform clay. Paper presented at: In Proc., Int. Symp. on Frontiers in Offshore Geotechnics, ISF-OG052005; Perth, Western Australia.

[132] Song Z, Hu Y, Randolph MF. Numerical simulation of vertical pullout of plate anchors in clay. Journal of Geotechnical \& Geoenvironmental Engineering. 2008;134(6):866-875.

[133] Wang D, Hu YX, Randolph MF. Three-dimensional large deformation finite-element analysis of plate anchors in uniform clay. Journal of Geotechnical \& Geoenvironmental Engineering. 2010;136(2):355-365.

[134] L. YU, Liu J, Kong XJ, Y. HU. Numerical study on plate anchor stability in clay. Géotechnique. 2010;61(3):235-246.

[135] Yu SB, Hambleton JP, Sloan SW. Undrained uplift capacity of deeply embedded strip anchors in non-uniform soil. Computers \& Geotechnics. 2015;70:41-49.

[136] Chen Z, Tho KK, Leung CF, Chow YK. Influence of overburden pressure and soil rigidity on uplift behavior of square plate anchor in uniform clay. Computers \& Geotechnics. 2013;52(7):71-81.

[137] Tho KK, Chen Z, Leung CF, Chow YK. Pullout behaviour of plate anchor in clay with linearly increasing strength. Canadian Geotechnical Journal. 2013;51(1):92-102.

[138] Wu X, Chow YK, Leung CF. Behavior of drag anchor under uni-directional loading and combined loading. Ocean Eng. 2017;129:149-159.

[139] Wu X, Chow YK, Leung CF. Behavior of drag anchor in clay with linearly increasing shear strength under unidirectional and combined loading. Appl Ocean Res. 2017;63:142-156.

[140] Bransby MF, o'Neill MP. Drag anchor fluke-soil interaction in clays. In Proc. Int. Symp. on Numerical Models in Geomechanics (NUMOG VII); 1999.

[141] O'Neill MP, Bransby MF, Randolph MF. Drag anchor fluke- soil interaction in clays. Canadian Geotechnical Journal. 2003;40(1):78-94.

[142] Elkhatib S, Randolph M. The effect of interface friction on the performance of drag-in plate anchors. Paper presented at: Proc., Int. Symp. on Frontiers in Offshore Geotechnics, IS-FOG052005.

[143] Elkhatib S. The behaviour of drag-in plate anchors in soft cohesive soils, University of Western Australia; 2005.

[144] Yang M, Murff JD, Aubeny CP. Undrained capacity of plate anchors under general loading. Journal of Geotechnical \& Geoenvironmental Engineering. 2010;136(10):1383-1393.

[145] Cassidy MJ, Gaudin C, Randolph MF, Wong PC, Wang D, Tian Y. A plasticity model to assess the keying of plate anchors. Géotechnique. 2015;62(9):825-836.

[146] Wei Q, Cassidy MJ, Tian Y, Gaudin C. Incorporating shank resistance into prediction of the keying behavior of suction embedded plate anchors. Journal of Geotechnical \& Geoenvironmental Engineering. 2015;141(1):04014080. 
[147] Liu J, Lu L, Hu Y. Keying behavior of gravity installed plate anchor in clay. Ocean Eng. 2016;114:1024.

[148] Seidel M, Mutius MV, Rix P, Steudel D. Integrated analysis of wind and wave loading for complex support structures of Offshore Wind Turbines. 2005.

[149] Agarwal P, Manuel L. Simulation of offshore wind turbine response for long-term extreme load prediction. Eng Struct. 2009;31(10):2236-2246.

[150] Jensen JJ, Olsen AS, Mansour AE. Extreme wave and wind response predictions. Ocean Eng. 2011;38(17-18):2244-2253.

[151] Haselbach P, Natarajan A, Jiwinangun RG, Branner K. Comparison of coupled and uncoupled load simulations on a jacket support structure Energy Procedia. 2013;35(41):244-252.

[152] Mardfekri M, Gardoni P. Probabilistic demand models and fragility estimates for offshore wind turbine support structures. Eng Struct. 2013;52(52):478-487.

[153] Saha N, Gao Z, Moan T, Naess A. Short-term extreme response analysis of a jacket supporting an offshore wind turbine. Wind Energy. 2014;17(1):87-104.

[154] Wei K, Arwade SR, Myers AT. Incremental wind-wave analysis of the structural capacity of offshore wind turbine support structures under extreme loading. Eng Struct. 2014;79:58-69.

[155] Kim DH, Lee SG. Reliability analysis of offshore wind turbine support structures under extreme ocean environmental loads. Renewable Energy. 2015;79(1):161-166.

[156] Jiang Z, Hu W, Dong W, Gao Z, Ren Z. Structural reliability analysis of wind turbines: a review. Energies. 2017;10(12):2099.

[157] Ziegler L, Voormeeren S, Schafhirt S, Muskulus M. Sensitivity of wave fatigue loads on offshore wind turbines under varying site conditions. Energy Procedia. 2015;80:193-200.

[158] Chew KH, Tai K, Ng EYK, Muskulus M. Analytical gradient-based optimization of offshore wind turbine substructures under fatigue and extreme loads. Marine Structures. 2016;47:23-41.

[159] Ruiter MJD, Zee TJJVD. Improved simulation of wave loads on offshore structures in Integral design load case simulations Energy Procedia. 2016;94:199-206.

[160] Shi W, Tan X, Gao Z, Moan T. Numerical study of ice-induced loads and responses of a monopiletype offshore wind turbine in parked and operating conditions. Cold Regions Science \& Technology. 2016;123:121-139.

[161] Lin YH, Chen JF, Lu PY. A CFD model for simulating wave run-ups and wave loads in case of different wind turbine foundations influenced by nonlinear waves. Ocean Eng. 2017.

[162] Yeter B, Garbatov Y, Soares CG. Evaluation of fatigue damage model predictions for fixed offshore wind turbine support structures. Int J Fatigue. 2016;87:71-80.

[163] Argyriadis K, Klose M. Analysis of offshore wind turbines with jacket structures. 2007.

[164] Yeter B, Garbatov Y, Soares CG. Spectral fatigue assessment of an offshore wind turbine structure under wave and wind loading. 2014.

[165] Yeter B, Garbatov Y, Soares CG. Fatigue reliability assessment of an offshore supporting structure. 2015.

[166] Long H, Moe G. Preliminary design of bottom-fixed lattice offshore wind turbine towers in the fatigue limit state by the frequency domain method. Journal of Offshore Mechanics \& Arctic Engineering. 2012;134(3):031902.

[167] Li H, Hu Z, Wang J, Meng X. Short-term fatigue analysis for tower base of a spar-type wind turbine under stochastic wind-wave loads. International Journal of Naval Architecture \& Ocean Engineering. 2017;10(1).

[168] Schafhirt S, Page A, Eiksund GR, Muskulus M. Influence of soil parameters on the fatigue lifetime of offshore wind turbines with monopile support structure. Energy Procedia. 2016;94:347-356. 